NASA Technical Memorandum 81685

(NASA-TA-81685) SERT II 1980 EXTENDED

FLIGHT THROSTER EXPERIHENTS (NASA) $27 \mathrm{p}$

N8 1- 19222

HC A 03/AIF AO1

CSCL 21C

$63 / 20 \quad 41728$

\title{
Sert II 1980 Extended Flight Thruster Experiments
}

W. R. Kerslake and L. R. Ignaczak

Lewis Research Center

Cleveland, Ohio



Prepared for the

Fifteenth International Electric Propulsion Conference cosponsored by the American Institute of Aeronautics and Astronautics, the Japan Society for Aeronautical and Space Sciences, and Deutsche Gesselschaft fur Luft- und Raumfahrt

Las Vegas, Nevada, April 21-23, 1981 


\section{SERT II 1980 EXTENDEO FLIGHT THRUSTER EXPERIMENTS}

by W. R. Kerslake and L. 'R. I gnaczak

National Aeronautics and Space Administration

Lewis Research Center

Cleveland, Ohio 44135

\section{Abstract}

The SERT II spacecraft, launched in 1970, has been maintained in an operational, but intermittent status since 1971. This paper presents the flight results obtained from mid 1979 through December 1980. Near continuous solar power in 1979 and 1980 has enabled long periods of thruster endurance testing. Three of four propellant tanks have been exhausted with no significant change in thruster system operation before being empty. A new plasma mode thrust has been characterized and direct thrust measurements obtained. Other tests, including beam neutralization by various neutralizer sources, give insight to electron conduction across plasmas in space and provide a basis to model neutralization of thruster arrays.

\section{Introduction}

The Space Electric Rocket Test 11. (SERT II) spacecraft was launched in 1970 with a primary objective of demonstrating long-tern operation of a space electric thruster system ${ }^{1}$. Progress towards that object ive was completed late in 1970 when each of two ion thruster systems on board developed a high-voltage grid short. The continuing functional state of the spacecraft has permitted an expansion of the original scope of mission to include demonstration of ion thruster system space storage, restartability, and steady state operation, and the study of plasma efflux between two thruster system ${ }^{3}$. These added tests were possible since the spacecraft returned to a continuous sunlight orbit on January 11, 1979 and continuous power is available to perform testing until April 1981 (est.).

This paper presents the results of SERT II experiments conducted in the period of mid 1979 to December 1980. These results include: (1) verification of flow rates measured on earth in vacuum tanks with flow rates measured on board SERT II; (2) thruster system operating characteristics (startup or steady state) remained stable during this operation; (3) indentification of a plasma thrust mode (H.V. off) of the discharge chamber and obtaining direct thrust measurements of this mode; (4) operating an ion beam while emitting neutralizing electrons from various sources; and (5). operating an ion thruster with no on-board neutralizer emitter.

During the period of December 1980 to April 1981, thruster system 2 is planned for plasma mode operation to obtain further discharge chamber endurance operation and exhaust the main propellant tank to obtain confirmation of its flow rate. In Apri] 1981, the spacecraft orbit will enter an era of partial shadowing for eight years (except October-November 1981). In 1989 continuous sunlight orbits would again occur. No plans presently exist for any spacecraft testing past Apri] 1981.

Nomenc lature

I

$n_{i}$

Neut

Main

$S / A$

$S / C$

Supply 4

Supply 5

Supply 6

Supply 7

Supply 10

$\mathrm{T} / \mathrm{S}-1$

$\mathrm{T} / \mathrm{S}-2$

$V_{S}$
Supply 9

\author{
current, $\mathrm{mA}$ \\ ion plasma density, ions $/ \mathrm{cm}^{3}$ \\ neutralizer \\ main discharge of thruster \\ solar array \\ spacecraft \\ main discharge \\ screen (beam) current (i.e., 2-15 \\ is beam current of $T / S-2$ ) \\ accel grid \\ neut keeper \\ neut bias \\ main keeper \\ thruster system 1 \\ thruster system 2 \\ volt age, $v$ \\ space plasma potential \\ (assumed $=$ zero $\mathrm{v}$ ) \\ Apparatus and Procedure
}

The SERT II spacecraft is shown in Fig. 1. It consists of an Agena stage rocket with a $1.5-\mathrm{kW}$ solar array on one end and two experimental ion thruster systems on the opposite end. Further description of the spacecraft and its operation may be found in Refs. 2 to 4 . A thruster system contains an ion thruster together with $\mathrm{Hg}$-loaded propellant tanks mounted on gimbals. A thruster power conditioning and control box is located inside the spacecraft body. Each thruster system has a hot-wire probe that can be swept through the ion exhaust beam and measure its plasma potential profile. The following sections describe this hardware and operating conditions in detail.

\section{Thruster Systems}

The steady-state SERT II thruster operation at various times since 1970 is summarized in Ref. 2 and Table 1 and 2. The information below gives normal thruster operation applicable to the data of this paper. The two thruster systems were identical in electrical and mechanical design.

$T / S-1$. - Data were attained with this thruster completely off, with the neutralizer discharge only lit, and with both the main and neutralizer discharges lit. Figure 2 shows a schematic wiring diagram of thruster power supplies and solar array. Various set points of operation may be found in data tables of this paper. The screen (I-V5) to accel grid (I-V6) short developed in 1970 remains, and prevented these supplies from turning on without current overload. The telemetry current return to $\mathrm{S} / \mathrm{C}$ ground, however, remains functional when the supplies are off. The I5 current reads electron return to $S / C$ ground or ions leaving the thruster. If a net flow of electrons should leave the thruster, the 15 current would read zero. The I6 current reads electrons flowing from $S / C$ ground to the accel grid due to ion imp ingement. If a net 
flow of electrons should strike the accel grid, the I6 current would read zero. With the V6 supply turned off, the impedance to electrons flowing from $S / C$ ground through the supply causes the accel grid to become $10 \mathrm{v}$. posit ive for $0.1 \mathrm{~mA}$ current, $29 \mathrm{v}$. positive for $6 \mathrm{~mA}$, and $47 \mathrm{v}$. positive for $22 \mathrm{~mA}$.

$T / S-2$. - For the tests described herein, the beam current of thruster 2 was maintained at $85 \pm 3$ $\mathrm{mA}$ or $200 \pm 3 \mathrm{~mA}$ by closed-100p control. The screen voltage was $3000 \mathrm{v}$ and the accel grid was $-1500 \mathrm{v}$. for $85 \mathrm{~mA}$ beam. The data tables give operating values of other parameters, such as when $T / S-2$ was operated in a plasma thruster mode ( $H . V$. off, ma in discharge on.)

V9 bias supply. - The v9 supply was designed - to place a bias voltage between the neutralizer cathode and $S / C$ ground. In addition to zero voltage, there are four nominal bias voltages: $\pm 25 \mathrm{v}$ and $\pm 50 \mathrm{v}$. The common of the bias supply is connected to S/C ground and the output then drives the neutralizer cathode either $(+)$ or $(-)$ with respect to the $S / C$ frame. The bias voltages were generated by flowing current across a zener diode stack with voltage magnitude and polarity changes made by a command switching network. Current to produce negative bias was produced internally within the supply, but neutralizer emission current was required to produce positive bias. At times, when there was little or no neutralizer emission, the nominal positive $V 9$ voltage did not. appear on the neutralizer. The I9 telemetry read emitted electron current from $S / C$ ground through the neutralizer cathode to space plasma. If electron flow was in the opposite direction, I9 telemetry would read zero.

Hot-Wire Prodes

The SERT II spacecraft was designed with three hot-wire emissive probes to measure plasma potentials 5 . One probe, which burned out in 1971, was at the end of a 1.5-meter long beam protruding ahead of the $S / C$ body. The other two. probes were each at the end of an arm that rotated it into and out of each ion beam. The two beam probes are shown in Fig. 3. Beam probe 1-was jammed and remained stationary in a position fully away from the beam center, but was electrically operative. The probe voltages listed in tables are data as received from the $S / C$ and are relative to $S / C$ frame. All plasma potentials shown on figures are relative to space plasma potential which is assumed zero.

Beam probe 2 functioned normally. When commanded, it began rotating and was heated at the same time. The telemetry system sampled the probe potential reading every 4 seconds. Fifty seconds were required to make one sweep. Possible probe reading positions are shown in $\mathrm{Fig} .3$. As the "probe-on" command and telemetry sampling times were not synchronized the positions of readings are not always those shown in Fig. 3. One sampling, however, must always occur in the ion beam. Micro switches stop, reverse sweep direction, and turn off the probe at each end of travel, leaving an arc of $60^{\circ}$ not traversed by the probe 2 sweep. Further details of probe operation may be found in Ref. 3 or 5 .
Solar Array

Description and 1979 performance curves for the SERT 11 main solar array (S/A) are presented in Ref. 2. The 1430-W (beginning of life; BOL) array was degraded to about 63 percent of BOL maximum power and this power limit prevented cross neutralization operation at ion beam currents greater than $85 \mathrm{~mA}$. For all tests the negative side of the S/A was connected to S/C ground. S/A operating voltages are listed in Table 2 and the small voltage variation is due to load change and voltage degradation.

The solar array was loaded to maximum power several times in 1980. These tests showed, within data accuracy ( \pm 2 percent), little change from date taken in 1979 (2). This is to be expected from a solar array that has been in orbit over 10 years and was on the "flat" portion of its degradation curve.

\section{Telemetry Data Accuracy}

All S/C data is in the form of 0 to 63 counts, but each parameter has its own scale factor. The list below give the value of 1 count change in each parameter. The uncertainty is \pm 0.5 count. Some of the values in Table 2 fall between counts due to a time averaging of the data. There is also uncertainty in the data of Table 2 due to the updating sequence of the telemetry. For example, I5 and I6 update every 30 seconds, but 19 and v9. update only once per minute. The probe voltages update every 4 seconds.

\section{Spacecraft Telemetry Values}

$\begin{array}{cc}\frac{\text { Parameter }}{\text { I5 }} & \text { 1-Count value } \\ \text { I6 } & 5 \mathrm{~mA} \\ \text { I9 } & 7.05 \mathrm{~mA} \\ \text { V9 } & 7 \mathrm{~mA} \\ \text { V10 } & 2 \mathrm{v} \\ \text { Probe voltage. } & 0.5 \\ \text { S/A } & 2.4 \mathrm{v} \\ & 1.5 \mathrm{~V} \\ \text { Results and Discussion }\end{array}$

\section{Ion Beam Thrusting}

A summary of operating hours for both thruster systems is presented in Table 1 . Table 2 presents representative values of detailed operating parameters of T/S-2 (thruster system 2 ). T/S-2 was operated 42 times in 1979-80 for a total of 606 hours at $85 \mathrm{~mA}$ beam and 58 hours at $200 \mathrm{~mA}$ beam. Solar array maximum power 1 imits, as anticipated, prevented operation at $250 \mathrm{~mA}$ beam for more than a few seconds during each of four attempts. T/S-2 thrust data taken in 1980 agreed with that measured in 1979 and that measured in 1970 ; i.e., $10 \mathrm{mN}$ at $85 \mathrm{~mA}$ beam and $22 \mathrm{mN}$ at 200 $\mathrm{mA}$ beam. Experimental accuracy was \pm 3 percent for $85 \mathrm{~mA}$ beam and \pm 1.5 percent for $200 \mathrm{~mA}$ beam. These thrust values were measured from the resulting changes in spacecraft sp in rate data, such as, shown in Fig. 4 for 1979-80. T/S-2 increased sp in rate and $T / S-1$ decreased spin rate. Details of this type of thrust measurement may be found in the appendix of Ref. 2 .

There has been no change in thruster performance over the $10-1 / 2$ year period of space opera- 
tion that included 4030 hours of operation $(2744$ with beam) and 261 restarts with $T / S-2$. An additional 110 hours of beam current was logged after the 4030-hour (next tank empty) point during distant-neutralizing tests described later. The main discharge of $\mathrm{T} / \mathrm{S}-2$ ran an additional 2635 hours after the 4030-hour point and is estimated to operate 2500 hours more before the main tank will be empty in March-April 1981.

T/S-1 beam operation was attempted ten times in 1979 80, but the H.V. short of 1970 remained. The description of its discharge operation is described below in the Plasma Mode and Durability testing sections.

\section{Distant Neutralization}

Reference 3 presented early data on distant neutralization, a term used to describe neutralization of $\mathrm{T} / \mathrm{S}-2$ beam by electrons emitted from the neutralizer of $T / S-1$, almost 1 meter away. Figure 5 (also in Ref. 3) shows a diagram of possible ion currents and plasma densities while in distant neutralization. One result of Ref. 3 that was difficult to explain, was that the neutralizer coupling voltage (between neutralizer and beam center) was lower in the distant coupling mode than for normal neutralization. Reference 6 suggested a model for coupling voltages that explained the relative ease (lower coupling voltage) of cross neutralization. This model used the thruster external magnetic fields and showed that neut-2 emission must cross magnetic lines to enter its beam plasma, while neut-1 emission can follow (without crossing) magnetic lines in a path reaching to the ion beam 1 meter away.

The fraction of emission coming from either neutralizer could be adjusted by varying a bias potential (V9, Fig. 2) to either neutralizer cathode. Figure 6 shows how this fraction changes with bias voltage in addition to corresponding changes in beam voltage and spacecraft voltage. The $83 \mathrm{~mA}$ beam data were from Ref. 3 while the 200 $\mathrm{mA}$ beam data are new in this paper.

The data of Fig. 6 show that for no bias voltage, most of the neutralizer emission came from the neutralizer near the ion beam. For $83 \mathrm{~mA}$ beam data, all emission could be put of $f$ from neut-2 by applying +34 volts bias to neut- 2 . Similiarly, a bias of +6 volts on neut -1 (neut- 2 at no bias) cut off all emission from neut-1. For $200 \mathrm{~mA}$ beam data, the neut-2 bias was set at its maximum value $(+46 \mathrm{v}$.$) , but still about half the$ emission came from neut-2. The lack of complete cut off was probably due to the higher beam plasma voltage (acting like a natural anode) at $200 \mathrm{~mA}$ beam and a fixed bias limit. The spacecraft voltage and beam voltage shown on Fig. 6 react to neutralizer bias as expected from Ref. 2 or 5 . (Space plasma potential is defined as zero.)

The increased difficulty of distant neutralization at $200 \mathrm{~mA}$ means that distant neutralization of a multiple thruster array, particularly at higher beam current, may not be as readily accomplished as first stated in Ref. 2. This is not to say that distant neutralization can not be accomplished on a mult $i$ array of 2 A beam current thrusters, merely that higher coupling voltages may be required.

\section{No Local Neutralizer}

The distant neutralization data taken in early $197 y^{3}$ was always modified by the fact that there was no way to operate an ion beam without having its local neutralizer also turned on. Simulated off conditions were achieved by applying positive bias to the local neutralizer cathode, but the on-board command sequences did not provide for separate disabling of the neutralizer. Therefore, a test plan was made to disable the neutralizer another way, that was, by operating it long enough to empty its mercury propellant tank. Then, even though commanded on, the neutralizer was incapable of significant emission because there was no mercury flow to establish a hollow cathode discharge. Under this condition the keeper electrode was at high $\left(\sim 250 v_{\text {. }}\right)$ starting voltage and the tip heater was at maximum power. Thermonic emission at the maximum power temperature $\left(1100^{\circ} \mathrm{C}\right)$ was less than $1 \mathrm{~mA}$.

Neut-2 tank was emptied on day 122 (May 1) 1980 and distant neutralization tests were run in which (1) the main-1 and neut-1 discharges were turned on to neutralize the ion beam from $T / S-2$ ( $\mathrm{Fig} .7(\mathrm{a})$ ), or (2) just neut-1 turned on ( $\mathrm{Fig}$. 7(b)). Later, when neut-1 propellant tank was empty, neutralization was accomplished from just the main-1 discharge (Fig. 7(c)). Figure 7 contains plots of ion beam plasma potential profiles taken with the movable hot wire probe of $T / S-2$. Voltages levels for the spacecraft and neut-1 are also shown and were determined by the probe for $T / S-1$ which was in a fixed position ${ }^{3}$ midway between $T / S-2$ and $T / S-1$. Thruster operating conditions for Fig. 7 as well as Figs. 8 and 9 may be found in Table 3 . (Each curve of the figures is given a number to key it to Table 3 . Pass numbers in Table 3 key it to spacecraft control room data.)

Figure 7(a) results show three curves: normal operation with local neutralization, (2) distant neutralizer with neut-2 biased off (1979), and (3) distant neutralization with neut-2 empty. As stated in the previous section, curve 2 shows a drop in beam plasma potential and coupling voltage when both. neutralizer discharges were operating, although all emission seems to be coming from the distant neutralizer. Curve 3 shows a 25-volt increase in beam plasma potential with the local (neut-2) neutralizer empty. Interestingly curves 1 and 3 have about the same spacecraft potential, and the 34 volts positive bias of neut-2 (curve 2) lowered the spacecraft potential by 10 volts.

A hypothesis offered by Domitz ${ }^{2}$ to explain the coupling voltages observed in Fig. $7(\mathrm{a})$ is the following: space charge neutralization of an ion beam may require only a small ( $-1 \mathrm{~mA})$ number of electrons which become trapped in the positive well of the beam plasma. The only electrons that need to be added are equal to those lost from this wel1. Current neutralization may be achieved by other paths external and perhaps far downstream from the local neutralizer. (For example, neutralizer electrons could flow into the space plasma and other space plasma electrons could current neutralize the beam.)

Curve 2 with emission biased to "zero" may have emitted a net current of $3 \mathrm{~mA}$ and still have shown zero counts on the telemetry channel. The 
neut-2 keeper potential was 28 volts above spacecraft potential and therefore a few volts above the "wing" plasma of curve 2. Hence electrons from the keeper discharge could have been easily. drawn into the beam to provide space-charge neutralization, while neut-l emission was providing the bulk of the current neutralization to space plasma. When the local neutralizer tank (neut-2) was empty and no keeper discharge was present, space charge electrons were drawn from further away and a higher coupling (beam plasma) potential resulted.

Figure $7(b)$ shows the effect of eliminating the plasma produced by the main-l discharge. Without this additional plasma density, apparently useful to aid electron conduction, the beam plasma potential must increase to draw sufficient electrons to itself. Figure 7(b) shows a normal beam profile for reference together with two corresponding neut-2 curves, but with the main-1 discharge off. In curve 5 , neut-2 empty, the beam plasma potential is not only high enough to excede the design range of the probe, it has considerably broadened in width, and the spacecraft potential was lowered. All these trends were apparently caused by the need for neutralizing electrons and the relative impedence (no main-1 discharge plasma) to electron diffusion.

The data of Fig. $7(\mathrm{c})$ were taken later in 1980 after neut-1 tank was also empty. In this case the only source of net electron emission was the cathode of the main-l discharge. For this case the shape of the beam plasma potential profile was about the same as for curve 5 (Fig. $7(b))$, but the apparent coupling voltage was increased and the spacecraft voltage was oriven to $-70 \mathrm{v}$. The maximum beam plasma voltage is speculation because the probe design limits were again exceeded.

The operating conditions of both curve 3 and 5 (Fig. 7 , neut-2 empty) were maintained for 2 days to obtain a thrust measurement with this type of neutralization. The result was a thrust of $9.9 \mathrm{mN}$ ( \pm 5 percent) for curve 3 and $10.0 \mathrm{mN}$ ( \pm 3 percent) for curve 5. Both these values were essentially the same as for normal neutralization-measured thrust ${ }^{2}$ of $10.0 \mathrm{mN}( \pm 3$ percent). Apparent ly no appreciable beam diverange was introduced by the distant neutralization, nor did the greater beam potential affect the thrust. This latter observation was not surprizing as the maximum calculated value would be proportional to the square root of the respective net accelerating voltage, i.e. $(3000-25) \mathrm{v}$. for curve $1,(3000-52) \mathrm{v}$. for curve 3 , and $\left(3000-85^{+}\right) v$. for curve. 5

The operating conditions of curve 6 could not be maintained for a long enough period to change the spacecraft spin rate and obtain a thrust measurement. This was due to the negative voltage magnitude of the spacecraft and a resulting large ( $>60 \mathrm{~mA}$ ) amount of ions attracted to the accelerator grid of $T / S-1$. The $>60 \mathrm{~mA}$ caused a built-in current overload protection circuit to trip and a cut back of the flow to the main-l discharge. As the flow cutback, the discharge density and accelerater grid current were reduced be low the trip point, thus permitting the flow to resume. This cyclic behavior was marginally stable, but never persisted for more than two hours. The change in sp in rate in two hours was equivalent to the un- certainty in reading the spin rate and no meaningful data resulted.

The most dramatic case of operation with no local neutralizer occurred when the conditions of Fig. 7 (c) (curve 6) above were being attempted, and T/S-1 shut off completely due to a 2 minuteoverload integration device incorporated into the system. Surprizingly, T/S-2 cont inued to operate at $85 \mathrm{~mA}$ beam current with no source of net electron emission. This condition lasted for $53 \mathrm{~min}-$ utes and data was obtained from the on-board tape recorder. Eventually $H$. V. trips occurred to T/S-2 and the overload integrator device shut T/S-2 down. The above conditions were repeated 3 times, but the system never remained operating long enough to obtain a spin-rate thrust measurement. The conditions during this type of operation are listed in Table 3 as curve 7 . No curve was plotted because the probe reading was always at its maximum value. This value indicated a spacecraft potential of $<-106 \mathrm{v}$. The actual value of spacecraft potential could have been any magnitude up to the positive H. V. (screen) of $3150 \mathrm{v}$. At such large negative spacecraft potentials the thrust should be severly reduced by beam turn around. Surprizingly, the accelerator grid, which was $-1400 v$ with respect to the already negative spacecraft, did not attract enough ions to trip its overload value of $60 \mathrm{~mA}$. The actual value was $33 \mathrm{~mA}$ as shown in Table 3. Apparently, the beam plasma shielded the accelerator grid and the remaining (85-33) $\mathrm{mA}$ of beam returned to other parts of the spacecraft where it was not sensed by telemetry.

The above case has not been fully modeled analytically, but space ions returning to the spacecraft were probably the order of $1 \mathrm{~mA}$ plus any sheath-enlargement factor. Change-exchange beam ions might have contributed an estimated $9 \mathrm{~mA}$ (Fig. 5) still leaving about $40 \mathrm{~mA}$ returning to other parts of the spacecraft or thruster ground shield. This flux of returning ions did not apparent damage to the spacecraft which functioned normally during the beam turn around operation. T/S-2 itself might have become a casuality to beam turn around, because a day later, while operating T/S-2 (neutralized by neut-1 and main-1) a permanent $H$. V. thruster body short-to-ground developed. H. V. shorts are discussed in a later section, but note that this short was not the same as the 1970-type which was a screen-to-accel grid short.

\section{Low-Mode Test.}

Low mode is a main propellant control problem that can exist if the propellant flow should exceed a critical value. Flow rates higher than the critical value cause a reduction in beam current for an increase in flow; thus, a normal control loop will drive to maximum flow and the beam current will become lower and lower. The purpose of this section is not to describe how to avoid low mode, but rather to publish flight data taken of beam plasma potential while a thruster was in low mode. T/S-2 went into low mode during a test in which $H$. V. was turned on with no preheat and before the main discharge was lighted. Excess propellant condensed in flow passages prior to lighting. Once lighted, heat from the discharge evaporated the condensed mercury and drove the flow rate past the critical flow point. (Norma) 
preheating for 5 minutes prevented this condensdtion.) The thruster remained in low mode for several hours before being commanded off. The data of Fig. 8 and Table 3 (curves $8-10$ ) were taken during this time.

Figure 8 shows the beam plasma potential profile for a $10 \mathrm{~mA}$ beam at $3140 \mathrm{v}$. net accelerating voltage, and for two profiles in which neut-2 was biased $+40 \mathrm{v}$. and $-34 \mathrm{v}$. Also shown are spacecraft potential level (measured by probe 1). and the respective neut-2 potential. Note all potentials were relative to space plasma which was assumed zero. The profile for no neut-2 bias was much flatter than for a normal beam. The reason may be an abundance of charge exchange plasma, caused by the high propellant flow rate, lowering the impedance of the neutralizer plasma bridge, or/and a lower coupling voltages due to the lower amount of neutralizer electrons needed at the low beam current. Biasing of neut-2 accentuated the profile as shown in Fig. 8.

\section{H. V. Shorts}

The table below summarizes $H$. V. shorts that have occurred on SERT II flight thrusters. From telemetry analysis of the $V 5$ and $V 6$ supplies it was possible to conclude that all shorts except No. 4 on T/S-2 were between $V 5$ and $V 6$, i.e., the screen and accelerator grid. Also concluded was that the value of the short was below $10 \mathrm{~K}$ ohms.

\begin{tabular}{ccccc} 
& \multicolumn{2}{c}{ T/S-1 } & \multicolumn{2}{c}{ T/S-2 } \\
Short no. & $\begin{array}{c}\text { Beam, } \\
\text { hr }\end{array}$ & Year & $\begin{array}{c}\text { Beam, } \\
\text { hr }\end{array}$ & Year \\
1 & 2385 & 1970 & 2011 & 1970 \\
2 & 3781 & 1970 & 2561 & 1979 \\
3 & & & 2626 & 1979 \\
4 & & & $2744 *$ & 1980
\end{tabular}

*This short between $2 \mathrm{~V} 5$ and thruster (spacecraft) ground, all other shorts between $V 5$ and $V 6$.

Short 1, T/S-1, was removed by a single shut down and normal preheat period. Short 2 still exists in $\mathrm{T} / \mathrm{S}-1$ after 300 thermal recycles and 20 attempts to sustain high voltage. $T / S-2$, short 1 , occurred in 1970 and was not cleared until. 1974 following a spacecraft spin manneuver which placed the thruster in a small artifical gravity of about $0.01 \mathrm{"g".} \mathrm{T/S-2,} \mathrm{short} \mathrm{2,} \mathrm{occurred} \mathrm{during} \mathrm{a} \mathrm{test}$ in which high voltage was applied with no discharge to measure grid insulator leakage. No leakage was found, but a H. V. grid short developed, possibly from a higher voltage stress on the grids. The $V 5$ and $V 6$ supplies produced 10-percent higher voltages without the normal beam load and these voltages might have bent a grid web fragment that was weakened in the prior 550 hours of beam operation. Short 2 was cleared by a cold restart application of $H$. V. after several hot restarts failed $T / S-2$, short 3 , occurred during another test of H. V. application with no discharge. In this case the main discharge lighted, produced a beam current for' 2 to 15 seconds, and then T/S-2 developed a V5-V6 short. Several hot and cold restarts of high voltage were tried before the short finally cleared following a long heated period. The last short of T/S-2 was a short of $<10 \mathrm{~K}$ ohms between $2 \mathrm{~V} 5$ and thruster ground. This short occurred after $1-1 / 2$ hours steady state operation at $85 \mathrm{~mA}$ beam with neutralization from neut-1/main-1, and also one day after operating T/S-2 for 53 minutes with no neutralizer source. Short 4 still remains despite sixteen thermal recycling efforts to clear it.

The V5-V6 shorts were believed caused by neutralizer discharge ions striking the accel grid, causing erosion and web fragments to be produced. The web fragments would be electrostatically drawn to and short to the screen grid. The V5-ground short location was not as apparent. The most probable area was a plate attached to the thruster ground screen, underneith the neutralizer cathode. This plate was in close proximity $(\sim 3 \mathrm{~mm})$ to a surface of the thruster body ( $V 5$ potential).

\section{Plasma Beam Thrust}

Plasma beam thrust is a new SERT II thrust operating mode (utilizing only the main discharge chamber plasma) that was discovered by chance in late 1979. At that time T/S-1 main discharge was turned on and allowed to run continuous for endurance testing. After several days, it was noticed that the spacecraft spin rate was changing at a rate greater than normal! T/S-1 was producing thrust, about $0.8 \mathrm{mN}$, with no (V5 and $V 6$ turned off, see Fig. 2) voltages on the accelerator grids. Furthermore, no ion beam was indicated by telemetry measuring circuits.

What apparently happened was that the main discharge (V4) produced a mercury plasma at the level of the $v 4$ voltage, $40 \mathrm{v}$. This plasma diffused through the accelerator grids, carrying an equal number of electrons and ions. Once by the grids the ions were accelerated through a $40 \mathrm{v}$. sheath, producing a thrust beam. Electrons somehow were either carried along by the ion space charge or diffused into space plasma. This type of plasma beam acceleration has been studied earlier ${ }^{7}$. In this study ${ }^{\circ}$, however, the arc source, which was similar to an electron bombardment discharge chamber, had no grids to impede the acceleration of plasma or ions from the discharge chamber.

In any event, $T / S-1$ was producing thrust and the main discharge supply was the only supply that could give energy to produce a thrust beam. Subsequently, other tests were run at lower discharge voltage, which dropped the thrust level, and with the other thruster system, which produced about the same level of thrust. The thrust measured for 16 plasma beam thrust tests on SERT II is shown in Table 4 . Also in Table 4 are thruster operating conditions, estimated flow rate (from ground tests in $1970^{8}$ and $1980^{9}$ ), est imated floating levels of the $V 5$ and $V 6$ supplies, 9 and a calculated plasma beam ion current. The beam calculation assumed a one-dimensional ion beam of net energy as listed in Table 4 . The actual plasma beam has some degree of divergence, which if incorporated in the calculated ion current, would increase the ion current (perhaps by 20 percent). A qualitative idea of the divergence may be seen on p. 37 of Ref. 10, or in Fig. 9 of this paper. The nominal performance of the thruster operating in the plasma thrust mode is listed below: 


$\begin{array}{ll}\text { Thrust } & 0.8 \mathrm{mN} \\ \text { I sp, corrected } & 300 \mathrm{sec} \\ \text { Power (discharge only) } & 80 \mathrm{~W} \\ \text { Flow rate } & 1 \mathrm{gm} / \mathrm{hr} \\ \text { Power/thrust } & 100 \mathrm{~W} / \mathrm{mN}\end{array}$

The plasma potential of the plasma beam for T/S-2 is shown in Figs. $9(a)$ and (b) for two cases of neutralizer keeper discharge on and off, respectively. Figure $9(a)$ curve 11 shows a broad, but relatively flat potential profile as compared to the ion beam profiles of Fig. 7. When the neut-2 was biased to $-44 \mathrm{v}$., the potential edge of the plasma beam becomes better defined and a negative well was formed on either side. Biasing of the neutralizer exhibited potential control of the spacecraft as if the normal ion beam were operating. The design of the bias supply ${ }^{3}$ did not permit positive bias while in the plasma beam mode, so negative spacecraft voltages were not. demonstrated.

Figure 9 (b) shows plasma potential profiles after neut-2 tank became empty and no neutralizer keeper discharge was on. The center of the plasma beam becomes highly positive (curve 13) and the plasma beam potential profile is broadened over that shown in Fig. 9(a) (neut. operating). The corresponding thrust produced dropped from 0.8 to $0.5 \mathrm{mN}$ and the spacecraft potential dropped from -10 to $-20 \mathrm{v}$. By turning on neut-1, the positive plasma beam potential was reduced, as shown by curve 14, and the spacecraft potential was raised. By applying $-46 \mathrm{v}$. bias to neut-1, the positive plasma beam potential was further reduced and the spacecraft potential raised.

The identification and measurement of the plasma beam thrust should be an aide to designers of future electric propulsion spacecraft. For, example (1) an ion thruster in the plasma beam mode might be used for spacecraft attitude or potential control without the used for a highpower thruster to be on; (2) an ion thruster in a discharge warm-up mode will produce thrust and might require adjustment to account for disturbing torques; and (3) if an ion thruster has suffered a H. V. failure, it could still produce useful thrust in the plasma beam mode.

\section{Durability Testing}

\section{Main Cathodes}

The main cathode of T/S-1 operated for 7837 hours and 240 restarts before the main propellant tank became empty. During this period there was no noticible change in cathode performance as evidenced by no trend in main discharge nor keeper discharge. Cathode starting times varied from 0.3 to 9.5 minutes depending on initial system temperature. (Design specification was to light in 90 minutes of preheat.) Furthermore, as seen in Table 5, no change occurred in cathode t ip heater resistance over the operating period. Main cathode of $T / S-2$ is still operating at the time of this writing (Dec. 1, 1980), and has accumulated 6542 hours of running with 300 restarts demonstrated. As for $\mathrm{T} / \mathrm{S}-1$ main cathode, this main cathode was operated without detectable change in its main and keeper discharges, or in its tip heater resistance (Table 5). It has started very reliably, particularly in the last two years. (During 1974-76, while the spacecraft was in deep shadow periods, some what longer starting times (10 to 41 min.) were required to warm up to starting conditions.)

The successful operation of the main discharge chambers for near 8000 hours in space has bearing on the concerns evidenced in Ref. 11. Reference 11 addressed sputtering in mercury bombardment thrusters and the effect of reduced sputtering resulting from adsorbed vacuum tank gases. Referencell presented sputtering data over a range of vacuum tank pressures, including operation down to the 10-7 torr range which is difficult to obtain. The authors of this paper believe that Ref. 11 was correct in assuming that extrapolating down from the high 10-7 torr range was sufficient to indicate erosion rates to be expected in space, which is 3 orders of magnitude or lower, pressure. The SERT II data, however, is proof that no dramatic change in discharge chamber erosion will occur in the ultra-low vacuum of space.

\section{Neutralizer Cathodes}

The performance of the neutralizer cathodes equals that of the main cathodes, i.e., there was no noticible change in discharge characteristics, restarting was consistant, and tip heater resistance was unchanged over the full test time. The table below summarizes the totals for the neutralizer cathodes. Reference 12 correlated restart time to initial system temperature which was the main variable affecting start time.

\section{Neutralizer cathodes}

$\begin{array}{cccc}\text { System } & \begin{array}{c}\text { Total, } \\ \text { hr }\end{array} & \text { Restarts } & \begin{array}{c}\text { Restart time, } \\ \text { min }\end{array} \\ \text { T/S-1 } & 4919 & 222 & 3 \text { to } 7 \\ \text { T/S-2 } & 3870 & 261 & 3 \text { to } 7\end{array}$

Main Keeper Insulator

Figure 10 shows some of the construction details of the main cathode keeper electrode design. This design has proven satisfactory for. 7837 .hours of operation and 300 restarts over.a 10 year period in space. Features of the design included a solid tantalum electrode and a swaged insulator support tube. The electrode was made of a. refractory metal to resist melting. The normal operating oischarge heat load was only several watts, but during starting transition from high voltage, the heat load may be 35 watts. The starting transition, although usually brief $<1$ min.), may last longer if the mercury flow rate does not increase promptly to its full value. The swaged insulator was undercut to improve resistance to surface contamination, and a line-of-sight baffle was located as shown in $\mathrm{Fig}$. 10 to reduce the flux of sputtered metal on the exposed end insulator.

The resistance of this design to contamination can be inferred by the data of $F$ igs. 10(a) and (b), for thruster systems 1 and 2, respectiveiy. These data give the change in keeper voltage. with operating time. As there was no telemetry channel to measure main keeper current, any insulator leakage current must be inferred by changes in the keeper voltage and a known I-V curve of the 
keeper power supply. The data of Fig. 10 were taken during preheat conditions when voltage was applied, but no mercury flow was present to start a discharge. The data show a slight decrease in keeper voltage with time. This change in keeper voltage resulted in no apparent change in starting or operation of the main cathode. The uncertainty range of the data is due to $\pm 1 / 2$ count difference in measured keeper voltage and solar array input voltage. Leakage currents, estimated from I-V load curves, are shown on Fig. 10 to give the: reader an idea of the magnitude of this current. (The "roll-off" or I-V slope of each supply was unique and accounted for the varience between Figs. $10(a)$ and (b) in the values of leakage current shown.)

The conclusions from Fig. 10 were: (1) no problem resulted from the small amount of leakage current that occurred, (2) this current increased with time, probably due to surface build up at the exposed end of the swaged insulator, (3) future insulator designs should be at least equivalent to that used, and (4) the roll-off design of the keeper voltage supply should provide adequate starting voltage for end-of-life leakage currents as high as $20 \mathrm{~mA}$.

\section{Neutralizer Keeper Insulator}

Figure 11 shows some of the construction detail of the neutralizer keeper electrode design. The sketch is to scale with the $\mathrm{Al}_{2} \mathrm{O}_{3}$ insulator being $0.6 \mathrm{~cm}$ across. Insulator shielding design included the keeper electrode itself and a spacer washer between the keeper and $\mathrm{Al}_{2} \mathrm{O}_{3}$ block to minimize contact between the two. (In retrospect, a spacer washer probably should have been used under the screw head, also.) The electrode was tantalum to avoid melting for the same reasons noted above for the main cathode keeper.

Figure 11 also shows plots of neutralizer keeper leakage current with total operating hours for both flight thruster systems. The current was directly measured by telemetry before the discharge begins. The increase of this current with time probably was caused by a build-up of condensed sputtered metal on the $\mathrm{Al}_{2} \mathrm{O}_{3}$ insulator surfaces. This build-up may have been sputtered accelerator grid material (molybdenum). The curves are broken into sections of normal beam operation (dashed curve), no beam with neutralizer and main discharges lighted (dotted curve), and finally a period of only main discharge lighted (solid curve). Build up seemingly occurs during beam on periods, with a greater build up for thruster system 1 which had the longer beam on period. The no beam period was a time in which the leakage current apparently decreased. The authors formulate no reason for this decrease, but point out that this no-beam period included 9 calendar years for thruster system 1. The 9-year period for thruster system 2 occurred between the $250 \mathrm{~mA}$ and $85 \mathrm{~mA}$ beam operating periods. The final period was one of no accelerator grid erosion and no change in leakage currerit. Also, during this period, the leakage current could be measured more accurately because no neutralizer discharge occurs.

Figure 12 shows the semiconducting nature of the build-up film on the insulator. The data for
Fig. 12 was taken after the neutralizer $\mathrm{Hg}$ tanks were empty and a longer preheating time was possible to get leakage resistance values at thermal equalibrium. With $\mathrm{Hg}$ in the tank, the neutralizer discharge lighted in 3 to 7 minutes. Once

lighted, the telemetry read the sum of leakage plus discharge current, with the latter being much greater ( 5 to 10 times). The arrows on the data of $\mathrm{Fig}$. 11 indicate leakage current values that the authors believe would have been reached, had the discharge not lighted. The plotted circles are values of leakage current reached just before discharge lighting.

The conclusions reached from the data presented in Figs. 11 and 12 were: (1) the neutralizer keeper insulator shielding design was adequate, but not as good as that for the main keeper; (2) the insulator surface build-up resulted in leakage currents of 10 to $29 \mathrm{~mA}$ during neutralizer cathode lighting attempts, and a resulting falloff of keeper starting voltages from $420 \mathrm{v}$. to a range of 250 to $300 \mathrm{v}$; (3) even at the reduced keeper starting voltage, however, the neutralizer cont inued to relight upon command, (4) more attention should be given to future insulator shielding designs to prevent sputtered metal from reaching critical insulator areas; and (5) the design keeper voltage "roff-off" should provide for a leakage current margine of 10 to $20 \mathrm{~mA}$ at the minimum starting keeper voltage.

\section{H. V. Grid Insulators}

Tests were made on T/S-2 in late 1979 in which H. V. was applied to the grids before the thruster discharges had lighted. This was done both for a cool $\left(60^{\circ} \mathrm{C}\right.$ neut-2 tank) thruster and a warm (at normal operating temperature, $112^{\circ} \mathrm{C}$. neut-2 tank, $88^{\circ} \mathrm{C}$ ground screen) thruster. In both cases, there was no measurable leakage in either $15(<1.5 \mathrm{~mA})$ or $16(<0.1 \mathrm{~mA})$ for $V 5$ of 4020 $v$. and $v 6$ of $-1650 \mathrm{v}$. This result of no measurable insulator degradation agrees with results from thruster life tests in vacuum chambers and confirms the insulator design. The insulators were $\mathrm{Al}_{2} \mathrm{O}_{3}$ balls with double cup, line-ofsight, shields. The grid insulators of $T / S-1$, of course, could not be tested because of the H. $V$. grid short that was present.

\section{Neutralizer Propellant Tanks}

The neutralizer propellant tanks of each thruster system were operated until they became empty of mercury. This occurred on day 203, 1980 for thruster system 1 and day 122, 1980 for thruster system 2. The purpose of this section is to present detailed performance data of the neutralizer propellant tanks and compare this performance with design predictions.

A schematic cross section of a neutralizer tank is shown in Fig. 13. The tank consisted of two nearly equal volumes. One contain liquid mercury and the other contained a pressurizing gas ( 80 percent $\mathrm{N}_{2}, 20$ percent $\mathrm{Kr}$ ) (Krypton gas was added as a tracer gas for leak detection ground tests.) The two volumes were separated by a buty1 rubber bladder which terminated in an "0-ring" shape. This "0-ring" formed a seal between the two halves of the tank. A pressure transducer was mounted on the gas volume and a temperature sensor 
was located externally on the essentially isothermal tank.

As mercury flows out of the tank, the gas volume increased and the pressure decreased. A plot of this pressure decrease with operating time is shown in Figs. 14(a) and (b) for neutralizer tanks 1 and 2, respectively. (The pressure values were at discrete levels due to the telemetry count system used.) The use of the pressure change with time and the ideal gas law, permitted a calculation of the change in gas volume. The gas volume change was equal to the change of the mercury volume, and the mercury flow rate thus could be calculated. A second way to calculate the mercury flow rate was to integrate all flow periods after the tank is empty and divide into the total mercury loaded. Table 6 gives major flow periods for each neutralizer tank and respective data about flow rates. The flow rates based on the integrated total flow are in good agreement with ground based flow rate taken with "flow tubes" before launch. Flows rates earlier estimated,' based on the ideal gas law, were 10 to 20 percent higher than the integrated total flow rates. An error in the ideal gas low calculations was caused by not accounting for diffusion or leakage loss of pressurizing gas through the rubber bladder.

A complete analysis of gas diffusion was somewhat involved, but will be presented here because of possible impact on future propellant system design. There were two gas diffusion paths of interest. One was straight through the bladder from the gas side to the mercury side. This path was of no importance in the SERT II design, but may be significant in other designs. Any gas diffusing to the mercury side will become trapped, setting up a near equal back pressure and reducing the net diffusion rate. The only way for that gas. to escape would be past the "0-ring" seal or past the natural mercury seal formed by liquid mercury in the tube between the tank and the vaporizer. Neither of these escape paths were probable in the SERT II design. Future designs, however, should confirm that a natural mercury seal exists, that is, there is no surface roughness nor grooves on the tube inside wall that would allow gas to slip past the liquid seal. The second diffusion path of interest was the following: gas entered the rubber bladder, traveled sideways in the rubber until it reached the "0-ring." It continued through the rubber of the "0-ring" and escaped past the unsealed outer joint between tank-half flanges. Whereas this path was very tortuous, it did constitute the major path of pressurzing gas loss. The rate of pressurizing gas lost during storage periods of 1971 to 1978 was able to be measured (see Fig. 14(a) or (b)). The measured loss rates agreed within 20-percent with the calculated diffusion loss rate through the "0-ring" material.

During the storage periods the tank temperature was cooler $\left(35^{\circ}\right.$ to $\left.60^{\circ} \mathrm{C}\right)$ than when the thruster was operating $\left(98^{\circ}\right.$ to $\left.105^{\circ} \mathrm{C}\right)$. Literature values of butye rubber diffusion rates 13 . were used to extrapolate diffusion low rates during thruster operation at high temperatures: The diffusion rate was 25 times greater at $105^{\circ} \mathrm{C}$ than at $35^{\circ} \mathrm{C}$. The higher temperature diffusion rate value was used to correct the pressure decrease in the ideal gas low flow calculations.
When this was done, the flow rates thus calculated were within experimental error of those flow rates calculated from integrated total flow data.

After the mercury was empty $(4991 \mathrm{hr} T / \mathrm{S}-1$ and $3870 \mathrm{hr} \mathrm{T/S-2)}$ the gas reservoir pressure dropped rapidly. This drop in pressure was caused by gas diffusion directly through the butyl rubber bladder. The gas that diffused across the bladder was now more free to flow through the empty mercury propellant line, through the porous tungsten vaporizer plug and out through the neutralizer cathode orifice to space. The gas pressure decay curve was used to calculate a gas flow rate. This flow rate agreed with a flow rate calculated from butyl rubber diffusion rates, rubber thickness and surface area. The agreement was further supported by diffusion flow at two temperature levels giving two points of comparison. The two rates can be seen on Fig. 14(b): a low rate (tank cold) from 4120 to 6300 hours, and a high rate (tank hot) from 6300 to 9200 hours.

Conclusions based on neutralizer tank pressure data were:

(1) Neutralizer flow rate performance in space was the same as for ground vacuum chamber thruster operation over all conditions tested.

(2) The design of a butyl-rubber bladder blow-down tank was validated for a 10-year period with the following constraints; thermally design the tank to cool temperatures $\left(20^{\circ} \mathrm{C}\right)$ where gas diffusion through the bladder is low enough for mission life, or depend on the liquid mercury to seal or trap. the diffused gas.

(3) Under normal flow operation (some mercury remaining in tank) the loss of pressurizing gas was negliable. The total of any leakage plus diffusion measured over an 8-year storage period was only $1.7 \times 10^{-4} \mathrm{~cm}^{3} / \mathrm{hr}$ (STP). A small excess ( 10 to 15 percent) of pressurizing gas could provide for this loss, even over a 10 year system life.

(4) There were no known materials compatability problems. The neutralizer tank provided pressurized liquid mercury to the vaporizer for the full life of the tank capacity. There were no known leaks of mercury and the tank capacity was exhausted when anticipated. The leakage of pressurizing gas was less than specified for typical gas-tight construction and had no impact on the flow-life of the system.

\section{Ma in Propellant Tanks}

The design of the main propellant tank followed the same philosophies as for the neutralizer propellant tank, but the main tank was constructed in a larger size to hold $14 \mathrm{~kg}$ of mercury. Because the main tank was at high voltage, no pressure transducer was used to measure change of pressurizing gas with time. Hence, there was no way to estimate flow rate as the mission progressed. Once the main tank is empty, however, the est imated flow rates could be integrated and compared with the total used to give a measure of conf irmation of the actual flow rates.

The main propellant tank of T/S-1 became empty on December 1, 1980. Table 7 summarizes the 
operating hours and estimated flows 8 for main tank-1. The estimated integrated total flow was $13,830 \mathrm{gm}$ which was only 1.6-percent less than the useful mercury, $14,050 \mathrm{gm}$, loaded into the tank (50 gm of additional mercury was loaded into the line between the tank and vaporizer and was considered to be unavailable for use.) The 1.6percent difference probably resulted from the accuracy of the estimated flows while T/S-1 was in discharge operation. Discharge only operation flow rates accuracy was not emphasized in prelaunch tests because the original mission plan was to run but a few hours at discharge only, with the bulk of operation to be at full beam current. other uncertainties existed in the estimated "endeffects" of restarting, stopping and short clearing tests. All of these "end-effects," however, amount to a small total, and estimation inaccuracies were of no importance. Main tank-2, when run to exhaustion (est. time, March-April 1981), will give more infomation on main flow rates.

The authors believe that the 1.6-percent difference of main tank-1 constitutes excellant confirmation that a mercury bombardment thruster operated at essentially the same propellant utilization in space as measured in laboratory vacuum tanks.

Vaporizers

Because the vaporizers caused absoutely no trouble, their performance tended to be overlooked. Vaporizers were made of porous tungsten ( 2.4 micron bore diam, 70 and 76 percent dense) electron-beam welded into tantalum housings. Vaporizer design and flow information is documented elsewherei4. The SERT II flight vaporizers with stood flight qualification and launch vibration, 11 years in space, 5000 to 8000 hours of operation, and 300 restart.cycles, all without failure. The dynamic head (distance from tank to vaporizer) was kept small by design, so that no valve was necessary to withstand launch vibration pressures that might force liquid mercury through vaporizer pores. The vaporizer operating power with time (see tables 2 or 5 ) was nearly constant, and the small differences that were measured were probably a result of a varing thermal (sun-angle) environment more than anything else.

\section{Concluding Remarks}

As the greatly-extended life of the SERT II spacecraft is nearing completion, it is time to reflect on the accomplishments of this electric propulsion spacecraft. First, the 11-year useful life of a spacecraft designed for 18-months, is a tribute to the design and qualification team of Lewis Research Center employees and subcontractors that built the spacecraft in 1969. Next, the prime experiment, the ion thrusters, proved themselves with remarkably durable and high quality performance while accomplishing one mission objective after another. It is true that the main objective, 6-months operating time in space from one thruster system, was not reached in 1970; but one thruster did run for 5 months before a $H$. V. short stopped its beam. All other parts of the thruster system functioned as designed or better, unt il at last the propellant tanks became empty and testing was no longer possible.
Extended mission objectives accomplished were: (1) clearing the H.V. short from $T / S-2$ and reestablishment of normal thruster operation in 1979 and 1980 after 10 years space storage, (2) successfully demonstrating 300 restarts without difficulty, (3) operating discharge chambers for nearly 8000 hours (11 months) in-space, (4) documenting a new form of plasma beam thrust from a discharge chamber, (5) acquiring in space information on low-energy plasma interactions between thruster systems and between thrusters and spacecraft, and (6) the demonstration of "distant neutralization" of an ion beam from a neutralizer one meter away.

More than anything else gained, was the confidence that mercury bombardment ion thruster systems can be built and operated in space on a routine basis with the same lifetime and performance as measured in ground testing.

\section{References}

1. Kerslake, W. R., Goldman, R. G., and Neiberding, W. C., "SERT II: Mission, Thruster, Performance and In-Flight Thrust Measurements," Journal of Spacecraft and Rocket s, Vo 1. 8, Mar. 1971, pp. 213-224.

2. KersTake, W. R. and I gnaczak, L. R., "SERT II 1979 Extended Flight Thruster System Performance," AIAA Paper 79-2063, Oct. 1979.

3. Kerslake, W. R. and Domitz, S., "Neutralization Tests on the SERT II Spacecraft," AIAA Paper 79-2064, 0ct. 1979.

4. Ignaczak, L. R., Stevens, N. J. and LeRoy, B. E., "Performance of the SERT II Spacecraft after 4-1/2 Years in Space," NASA TM $X-71632,1974$.

5. Jones, S. G., Staskus, J. V., and Byers, 0. C., "Preliminary Results of SERT II Spacecraft Potent ial Measurements Using Hot-Wire Emissive Probes," AIAA Paper 70-1127, Sep. 1970; also NASA TM X-52856, 1970 .

6. Kaufman, H. R., "Plasma Physics Analys is of SERT II Operation," Colorado State Univ., Fort Collins, CO, Jan. 1980. (NASA CR-159814).

7. Burkhart, J. A., "Initial Performance Data on a Low-Power MPD Arc Thruster with a Downstream Cathode," AIAA Paper 70-1084, Aug. 1970.

8. Byers, D. C. and Staggs, J. F., "SERT II Flight-Type Thruster System Performance,". AIAA Paper 69-235, Mar. 1969.

9. Wilbur, P. J. "Ion and Advanced Electric Thruster Research," Colorado State Univ., Fort Collins, C0, 1981. (NASA CR-165253).

10. Wilour, P. J., "Physical Phenomena in Mercury Ion Thrusters," Colorado State Univ., Fort Collins, C0, Dec. 1979. (NASA CR-159784).

11. Mantenieks, M. A. and Rawlin, V. K., "Sputtering in Mercury Ion Thrusters," AIAA Paper 79-2061, Oct. 1979.

12. Kerslake, W. R. and Finke, R. C., "SERT II Hollow Cathode Multiple Restarts in Space," AIAA Paper 73-1136; Oct. 1973.

13. Rittenhouse, J. B. and Singletary, J. B., Space Materials Handbook, 3rd Edition, NASA SP-3051, 1969, p. 313.

14. Kerslake, W. R., "Design and Test PorousTungsten Mercury Vaporizers," AIAA Paper 72-484, Apr. 1972; also NASA TN D-6782, 1972. 
TABLE 1. - SUMMARY OF OPERATING HOURS

FOR SERT II THRUSTERS





aNeutralizer Hg tank empty at end of test hours.

ba in $\mathrm{Hg}$ tank empty, Dec. 1, 1980 at end of test hours.

$C_{\text {As }}$ of Dec. 8, 1980; still-operating (est. empty in 2500 more $\mathrm{hr}$ ). 


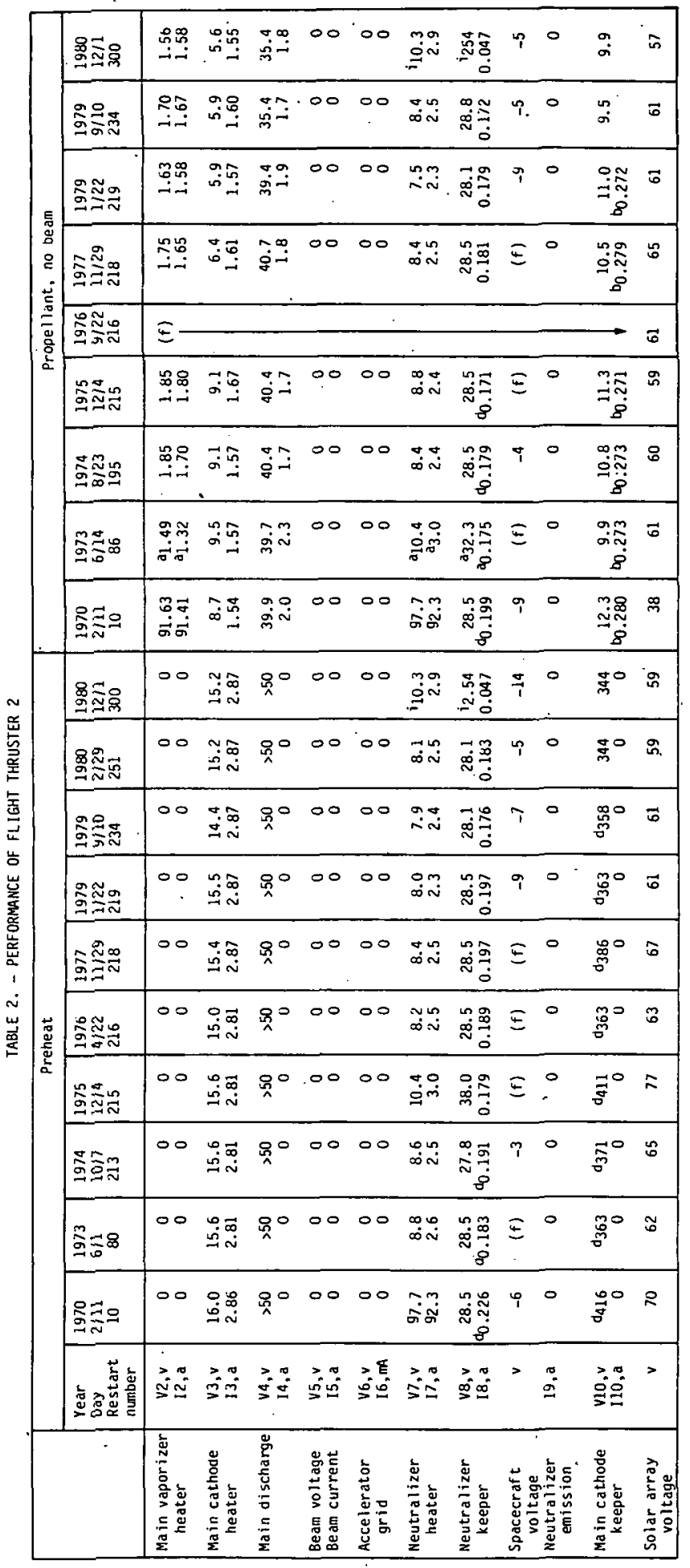

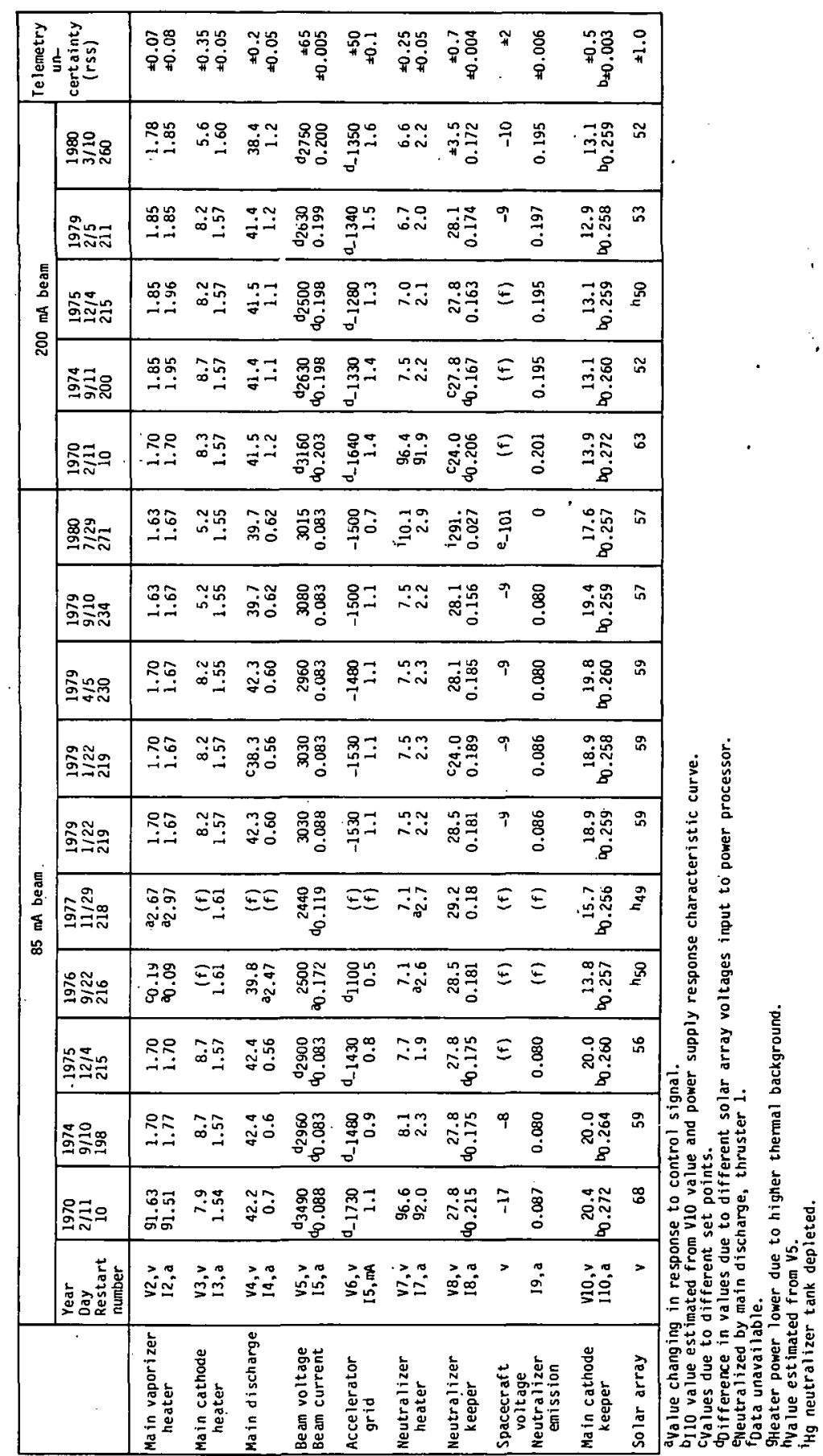




\begin{tabular}{|c|c|c|c|c|}
\hline & \multicolumn{3}{|c|}{ 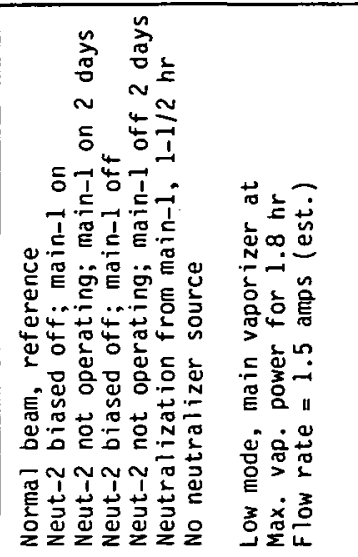 } & 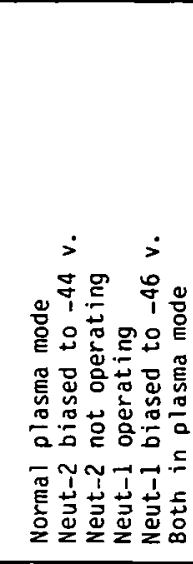 \\
\hline 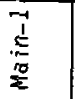 & 范 $\delta \delta^{4} 0^{4} \delta^{4} \delta^{4}$ & 俈出出范 & & \pm \\
\hline $\begin{array}{l}y \\
1 \\
y \\
y\end{array}$ & 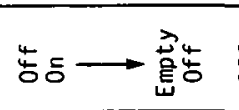 & 范范范 & & 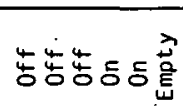 \\
\hline $\begin{array}{l}\tilde{y} \\
\frac{1}{\pi} \\
\frac{\pi}{2} \\
\end{array}$ & $\Xi \delta-$ & ธธธธ & & \\
\hline 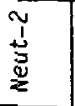 & 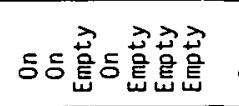 & $\delta \delta \delta$ & & $\delta$ 苔 \\
\hline$\sum>$ & $\vec{\Xi}^{\circ} \longrightarrow \cong$ & 조으 & & 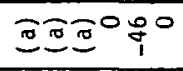 \\
\hline$D_{i=1}$ & ฮก & 可无 & & 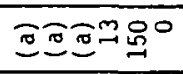 \\
\hline$\infty$ & 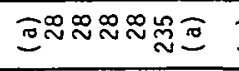 & 조응 & & తఠత⿱一⿻上丨 \\
\hline${ }_{0}^{\infty} \bar{\varepsilon}$ & 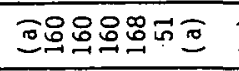 & 可苜 & &  \\
\hline 을 & 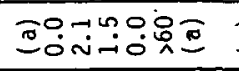 & 조음 & & 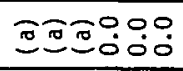 \\
\hline$\stackrel{m}{i}>$ & of & $\underset{+}{9} \circ \stackrel{9}{1}$ & & ${ }^{\prime}{ }^{\prime} \circ \longrightarrow$ \\
\hline कू⿻ & $\infty^{\circ} \longrightarrow$ & $m m m$ & & 융ㄱ \\
\hline$\stackrel{\infty}{\equiv}=$ & 赵志 & న & & 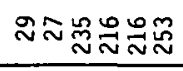 \\
\hline$\stackrel{\infty}{\approx} \tilde{E}$ & 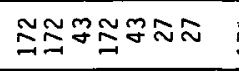 &  & \multirow{5}{*}{ 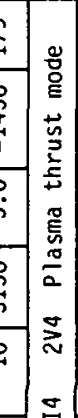 } & 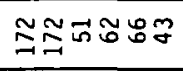 \\
\hline$\stackrel{\circ}{\approx}>$ & 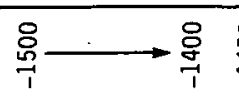 & 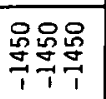 & & 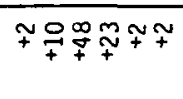 \\
\hline$\approx$ & 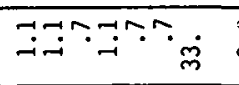 & 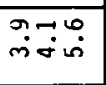 & & :- \\
\hline$\stackrel{2}{\vdots}$ & 总 $\longrightarrow$ 鸽 & 总角虽 & & F $\longrightarrow$ 品 \\
\hline$\approx$ & $\prod_{\infty}^{\infty} \infty \infty \longrightarrow$ & 으오으 & & $\stackrel{8}{\longrightarrow} \longrightarrow \stackrel{8}{-}$ \\
\hline 离 & tamoron & $\infty \pi 0$ & $\therefore$ & 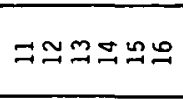 \\
\hline 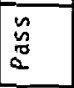 & $\approx \propto ⿻ コ 一 ⿻ 上 丨$ & $\nexists 28$ & & 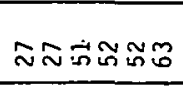 \\
\hline
\end{tabular}

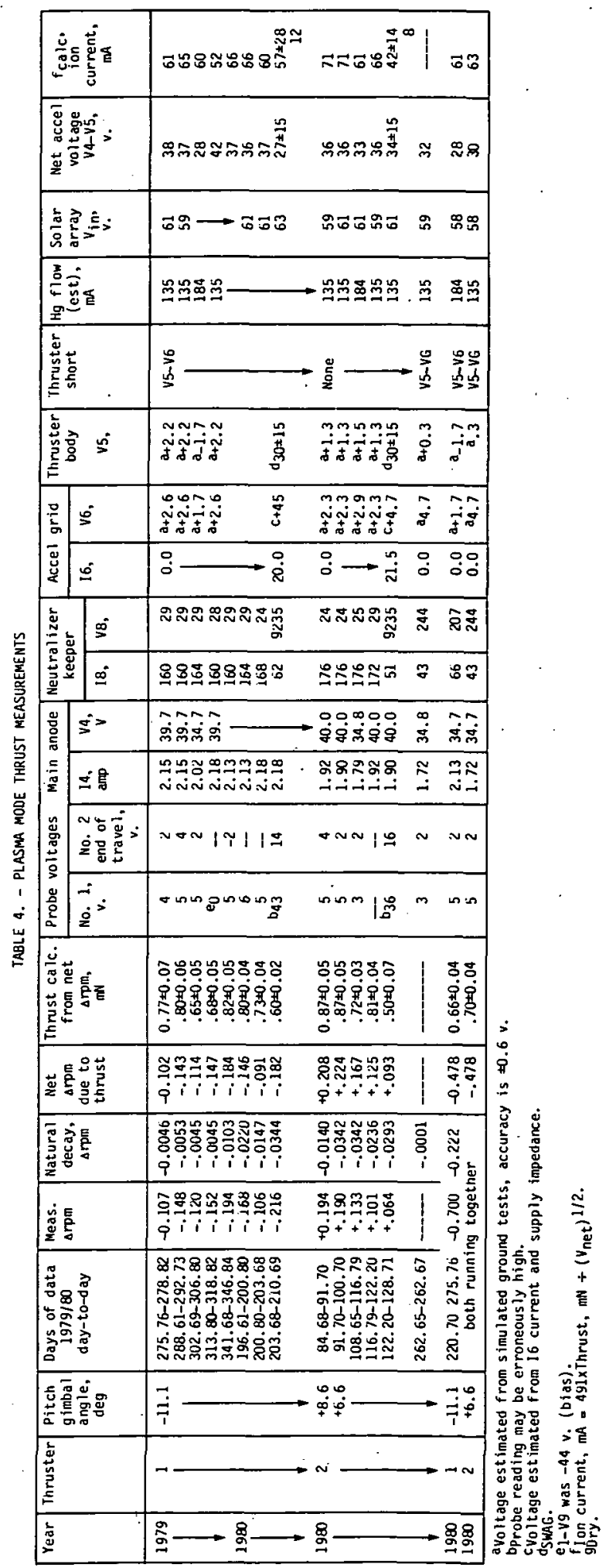


TABLE 5. - REPRESENTATIVE HEATER VALUES ${ }^{C}$ AND CATHODE STARTING TIMES

\begin{tabular}{|c|c|c|c|c|c|c|c|c|c|c|c|c|c|c|c|}
\hline \multirow[t]{2}{*}{ Thruster } & \multirow{2}{*}{$\begin{array}{l}\text { Start } \\
\text { number }\end{array}$} & \multirow[t]{2}{*}{ Date } & \multicolumn{3}{|c|}{ Main vaporizer } & \multicolumn{3}{|c|}{ Main cathode } & \multicolumn{3}{|c|}{ Neutralizer cathode } & \multicolumn{2}{|c|}{ Cathode start time } & \multirow{2}{*}{$\begin{array}{c}\text { Total } \\
\text { cathode, } \\
\text { on } \\
\text { time; } \\
\text { hr }^{\text {d }}\end{array}$} & \multirow{2}{*}{$\begin{array}{l}\text { Neutralizer } \\
\text { reservoir } \\
\text { temperature, } \\
{ }_{C}\end{array}$} \\
\hline & & & I2, & $v_{2}$, & $\mathrm{V} 2 / \mathrm{I} 2$, & I3, & v3, & $v_{3} / 13$ & 17, & $v 7$, & $v 7 / 17$ & $\begin{array}{l}\text { Neutralizer } \\
\text { cathode, } \\
\text { min }\end{array}$ & $\begin{array}{l}\text { Main } \\
\text { cathode, } \\
\text { min }\end{array}$ & & \\
\hline 1 & $\begin{array}{r}1 \\
4 \\
5 \\
.6 \\
7 \\
14 \\
20 \\
32 \\
33 \\
145 \\
156 \\
157 \\
160 \\
167 \\
172 \\
176 \\
177 \\
178 \\
179 \\
185 \\
191 \\
199 \\
212 \\
216 \\
222 \\
228 \\
230 \\
240\end{array}$ & $\begin{array}{l}12 / 9 / 69 \\
12 / 28 / 69 \\
2 / 14 / 70 \\
3 / 8 / 70 \\
5 / 21 / 70 \\
10 / 26 / 70 \\
2 / 11 / 71 \\
1 / 21 / 72 \\
5 / 25 / 73 \\
8 / 19 / 74 \\
10 / 9 / 74 \\
11 / 14 / 75 \\
9 / 15 / 76 \\
12 / 14 / 76 \\
7 / 27 / 77 \\
11 / 22 / 77 \\
7 / 14 / 78 \\
1 / 14 / 78 \\
1 / 17 / 79 \\
3 / 12 / 79 \\
5 / 22 / 79 \\
8 / 31 / 79 \\
12 / 5 / 79 \\
3 / 10 / 80 \\
7 / 15 / 80 \\
8 / 17 / 80 \\
10 / 23 / 80 \\
12 / 1 / 80\end{array}$ & $\begin{array}{l}2.80 \\
2.81 \\
2.81 \\
2.89 \\
\text { (a) } \\
2.89 \\
2.89 \\
\text { (a) } \\
2.81 \\
2.89 \\
2.81 \\
2.89 \\
2.09 \\
2.70 \\
2.79 \\
2.89 \\
1\end{array}$ & $\begin{array}{l}(a) \\
(a) \\
2.74 \\
(a) \\
2.67 \\
2.60 \\
2.67 \\
(a) \\
2.74 \\
1 \\
1 \\
2.10 \\
2.74 \\
2.74 \\
2.74 \\
2.67 \\
2.74 \\
2.67 \\
2.67 \\
2.67 \\
2.56 \\
2.70 \\
1 \\
1 \\
2.77 \\
2.70\end{array}$ & $\begin{array}{l}(a) \\
(a) \\
0.98 \\
(a) \\
(a) \\
.90 \\
.93 \\
(a), \\
.97 \\
.95 \\
.98 \\
.95 \\
1.00 \\
1.01 \\
.98 \\
.95 \\
.92 \\
.95 \\
.92 \\
.92 \\
.92 \\
.94 \\
.93 \\
.91 \\
.93 \\
.93 \\
.96 \\
.93\end{array}$ & $\begin{array}{c}2.80 \\
2.92 \\
2.88 \\
1 \\
\\
2.82 \\
1 \\
\\
\\
2.88 \\
2.82 \\
2.82 \\
2.88 \\
2.88 \\
2.82 \\
2.82 \\
2.88 \\
2.82 \\
2.82 \\
2.82 \\
2.87 \\
2.82 \\
2.87 \\
2.82\end{array}$ & \begin{tabular}{|l}
$>15$ \\
15.7 \\
15.7 \\
15.3 \\
15.3 \\
14.1 \\
15.7 \\
15.7 \\
15.3 \\
15.3 \\
15.7 \\
15.3 \\
14.5 \\
15.7 \\
$(\mathrm{a})$ \\
14.9 \\
1 \\
1 \\
14.5 \\
14.9 \\
14.1 \\
14.1 \\
14.4 \\
15.2 \\
14.8 \\
15.2 \\
14.4
\end{tabular} & $\begin{array}{r}>5.3 \\
5.4 \\
5.5 \\
5.3 \\
5.3 \\
4.9 \\
5.5 \\
5.5 \\
5.4 \\
5.4 \\
5.6 \\
5.4 \\
5.2 \\
5.5 \\
(a) \\
5.3 \\
5.2 \\
5.2 \\
5.3 \\
5.2 \\
5.2 \\
5.0 \\
5.0 \\
5.1 \\
5.3 \\
5.2 \\
5.3 \\
5.1\end{array}$ & $\begin{array}{c}2.78 \\
2.79 \\
2.90 \\
1 \\
1 \\
2.79 \\
2.90 \\
1\end{array}$ & $\begin{array}{l}\text { (a) } \\
9.9 \\
10.3 \\
10.6 \\
10.8 \\
10.8 \\
10.3 \\
10.1 \\
10.6 \\
10.8 \\
10.3 \\
10.6 \\
\\
\\
1 \\
10.3 \\
10.6 \\
10.3 \\
1 \\
1 \\
10.6 \\
10.6 \\
10.6 \\
10.3 \\
10.3\end{array}$ & $\begin{array}{l}\text { (a) } \\
3.6 \\
3.6 \\
3.7 \\
3.7 \\
3.7 \\
3.6 \\
3.6 \\
3.7 \\
3.7 \\
3.6 \\
3.7 \\
1\end{array}$ & $\begin{array}{r}8.5 \\
6.2 \\
3.3 \\
4.2 \\
4.3 \\
4.2 \\
4.2 \\
6.2 \\
6.6 \\
6.3 \\
6.8 \\
6.4 \\
6.5 \\
5.8 \\
6.6 \\
5.8 \\
6.5 \\
5.1 \\
4.8 \\
4.8 \\
6.6 \\
5.3 \\
6.2 \\
5.8 \\
\text { e4.4 } \\
---. \\
---. \\
--.-\end{array}$ & $\begin{array}{r}0.3 \\
.4 \\
.3 \\
.3 \\
.7 \\
b_{4} .4 \\
.3 \\
(a) \\
b_{6} .4 \\
7.4 \\
9.5 \\
3.8 \\
3.0 \\
7.2 \\
7.5 \\
3.1 \\
2.9 \\
1.5 \\
1.0 \\
4.0 \\
6.7 \\
1.7 \\
3.2 \\
3.3 \\
2.7 \\
2.0 \\
2.0 \\
e_{2} .7\end{array}$ & $\begin{array}{r}---- \\
--- \\
0 \\
508 \\
2283 \\
3794 \\
3855 \\
3868 \\
3869 \\
3885 \\
3889 \\
3890 \\
3891 \\
3894 \\
3896 \\
3897 \\
3898 \\
3898 \\
3904 \\
4046 \\
4085 \\
4093 \\
4498 \\
4624 \\
5080 \\
5164 \\
6896 \\
7838\end{array}$ & $\begin{array}{c}(a) \\
(a) \\
(a) \\
83 \\
78 \\
47 \\
83 \\
29 \\
(a) \\
1\end{array}$ \\
\hline 2 & $\begin{array}{r}1 \\
4 \\
10 \\
11 \\
12 \\
53 \\
67 \\
76 \\
126 \\
189 . \\
203 \\
211 \\
215 \\
216 \\
218 \\
219 \\
226 \\
230 \\
234 \\
251 \\
261 \\
275 \\
290 \\
300\end{array}$ & $\begin{array}{l}11 / 29 / 69 \\
12 / 21 / 60 \\
2 / 11 / 70 \\
7 / 24 / 70 \\
9 / 2 / 70 \\
11 / 13 / 70 \\
2 / 26 / 71 \\
1 / 21 / 72 \\
7 / 17 / 73 \\
8 / 19 / 74 \\
9 / 12 / 74 \\
10 / 2 / 74 \\
12 / 4 / 75 \\
9 / 22 / 76 \\
11 / 29 / 77 \\
1 / 22 / 79 \\
3 / 7 / 79 \\
4 / 3 / 79 \\
9 / 10 / 79 \\
2 / 29 / 80 \\
3 / 25 / 80 \\
8 / 9 / 80 \\
10 / 14 / 80 \\
12 / 1 / 80\end{array}$ & $\begin{array}{c}2.89 \\
2.90 \\
2.88 \\
2.97 \\
\downarrow \\
\text { (a) } \\
2.97\end{array}$ & $\begin{array}{l}\text { (a) } \\
(a) \\
2.77 \\
2.70 \\
1 \\
1 \\
(a) \\
2.70 \\
1\end{array}$ & $\begin{array}{l}\text { (a) } \\
\text { (a) } \\
.96 \\
.91 \\
\downarrow \\
\text { (a) } \\
.91 \\
1\end{array}$ & $\begin{array}{l}2.78 \\
2.77 \\
2.86 \\
2.86 \\
2.81 \\
2.81 \\
2.86 \\
2.86 \\
2.81\end{array}$ & $\begin{array}{c}>15 \\
16.0 \\
16.0 \\
16.0 \\
15.6 \\
15.6 \\
16.0 \\
16.0 \\
16.0 \\
15.6 \\
\\
\\
15.0 \\
15.4 \\
15.6 \\
14.8 \\
14.1 \\
14.8 \\
14.8 \\
14.8 \\
15.5 \\
15.5 \\
15.2\end{array}$ & $\begin{array}{l}\downarrow \\
5.7 \\
5.6 \\
\downarrow \\
5.3 \\
5.4 \\
5.3 \\
5.0 \\
4.8 \\
5.2 \\
5.2 \\
5.2 \\
5.4 \\
5.4 \\
5.3\end{array}$ & $\begin{array}{c}\downarrow \\
2.92 \\
1 \\
2.94\end{array}$ & $\begin{array}{l}\downarrow \\
10.2 \\
10.2 \\
10.4 \\
10.2 \\
10.0 \\
10.2 \\
10.4 \\
10.2 \\
10.1 \\
10.1 \\
10.1 \\
10.3 \\
10.3 \\
10.3\end{array}$ & $\begin{array}{c}1 \\
3.4 \\
3.4 \\
3.5 \\
3.5 \\
3.4 \\
3.5 \\
3.6 \\
3.5 \\
3.4 \\
3.4 \\
3.4 \\
3.5 \\
3.5 \\
3.5\end{array}$ & $\begin{array}{r}10.0 \\
6.3 \\
3.2 \\
3.2 \\
3.7 \\
2.8 \\
2.7 \\
5.3 \\
5.2 \\
5.4 \\
6.1 \\
6.8 \\
7.4 \\
6.2 \\
6.4 \\
3.9 \\
3.8 \\
3.2 \\
3.6 \\
4.2 \\
e .2 \\
--.-- \\
---- \\
----\end{array}$ & $\begin{array}{c}1.0 \\
1.0 \\
.4 \\
.9 \\
.9 \\
.9 \\
.4 \\
(a) \\
\mathrm{b} 8.2 \\
10.5 \\
22.5 \\
12.7 \\
29.3 \\
\mathrm{~b} 41.0 \\
2.1 \\
2.0 \\
1.8 \\
6.7 \\
2.8 \\
3.6 \\
3.3 \\
1.8 \\
2.0 \\
3.1\end{array}$ & $\begin{array}{r}--- \\
--0 \\
38 \\
934 \\
2094 \\
2126 \\
2149 \\
2162 \\
2166 \\
2169 \\
2175 \\
2177 \\
2178 \\
2279 \\
2342 \\
2757 \\
2881 \\
2890 \\
2985 \\
3026 \\
4200 \\
5502 \\
6542\end{array}$ & $\begin{array}{c}(a) \\
(a) \\
97 \\
97 \\
65 \\
69 \\
115 \\
33 \\
22 \\
43 \\
40 \\
35 \\
37 \\
30 \\
33 \\
62 \\
62 \\
97 \\
62 \\
66 \\
66 \\
59 \\
68 \\
115\end{array}$ \\
\hline
\end{tabular}

Data not taken or unavailable:

No preheat used.

cQuantizing and calibration error, \pm 3 percent, root-sum-square.

dincludes heating time in space only; ground time, thruster I - $83 \mathrm{hr}$, thruster $2-91 \mathrm{hr}$.

elast start-before $\mathrm{Hg}$ tank depleted. 
TABLE 6. - SUMMARY OF NEUTRALIZER FLOW RATES AND N2 OIFFUSION RATES

\begin{tabular}{|c|c|c|c|c|c|c|c|c|}
\hline \multirow[t]{3}{*}{ Period name } & \multirow{3}{*}{$\begin{array}{l}\text { Operating } \\
\text { period, } \\
\text { hr }\end{array}$} & \multirow{2}{*}{\multicolumn{2}{|c|}{$\begin{array}{l}\text { Differential } \\
\text { hours }\end{array}$}} & \multicolumn{3}{|c|}{ Mercury flow } & \multirow{3}{*}{$\begin{array}{c}\text { Tank } \\
\text { temp., } \\
\text { oC }\end{array}$} & \multirow{3}{*}{$\begin{array}{l}\mathrm{N}_{2} \text { loss by dif- } \\
\text { ussion (avg.), } \\
\mathrm{N} / \mathrm{cm}^{2} / \mathrm{hr}\end{array}$} \\
\hline & & & & \multicolumn{2}{|c|}{ Space } & \multirow{2}{*}{$\begin{array}{c}\text { Ground } \\
\text { Rate, } \\
\cdot \mathrm{mA}\end{array}$} & & \\
\hline & & Oper: & Calendar & $\begin{array}{c}\text { Total, } \\
\text { gms }\end{array}$ & $\underset{\pi A}{\text { Rate, }}$ & & & \\
\hline $\begin{array}{l}1969-70 \text { prelaunch testing } \\
1970 \text { normal beam, } 250 \mathrm{~mA} \\
1971-79 \text { restarts/storage } \\
1979-80 \text { plasma-mode operation }\end{array}$ & $\begin{array}{r}0-83 \\
83-3877 \\
3877-4166 \\
4166-4991\end{array}$ & $\begin{array}{r}83 \\
3794 \\
289 \\
825\end{array}$ & $\begin{array}{r}1248 \\
3815 \\
\mathrm{~b}_{81}, 100 \\
7600\end{array}$ & $\begin{array}{r}20 \\
650 \\
66 \\
188\end{array}$ & $\begin{array}{rr}22 \pm 2 \\
40 & (\text { est) } \\
46 \pm 6\end{array}$ & $\begin{array}{r}40 \begin{array}{r}\text { (est) } \\
18 \pm 1\end{array} \\
47 \pm 10\end{array}$ & $\begin{array}{r}23 \\
98 \\
\text { a } 35 \text { to } 60 \\
105\end{array}$ & $\begin{array}{r}0.006 \times 10^{14} \\
0.27 \times 10^{-4} \\
0.02 \text { to } 0.12: 10^{-4} \\
0.35 \times 10^{-4}\end{array}$ \\
\hline $\begin{array}{l}222 \text { cool down, after flow periods } \\
1980 \text { hot, Hg tank empty }\end{array}$ & C4991-6496 & - n & 1505 & $\begin{array}{r}0.9 \\
0\end{array}$ & $\overline{0}$ & ------- & 105 & $8.3 \times 10^{-4}$ \\
\hline
\end{tabular}

\begin{tabular}{|c|c|c|c|c|c|c|c|c|}
\hline \multicolumn{9}{|c|}{ (b) Neutralizer tank 2} \\
\hline \multirow[t]{3}{*}{ Period name } & \multirow{3}{*}{$\begin{array}{l}\text { Operating } \\
\text { period, } \\
\text { hr }\end{array}$} & \multicolumn{2}{|c|}{$\begin{array}{l}\text { Differential } \\
\text { hours }\end{array}$} & \multicolumn{3}{|c|}{ Mercury flow } & \multirow{3}{*}{$\begin{array}{c}\text { Tank } \\
\text { temp., } \\
\text { C. }\end{array}$} & \multirow{3}{*}{$\begin{array}{l}\mathrm{N}_{2} \text { loss by dif- } \\
\text { ussion (avg.), } \\
\mathrm{N} / \mathrm{cm}^{2} / \mathrm{hr}\end{array}$} \\
\hline & & \multirow{2}{*}{ Oper. } & \multirow{2}{*}{ Calendar } & \multicolumn{2}{|c|}{ Space } & \multirow{2}{*}{$\frac{\text { Ground }}{\substack{\text { Rate, } \\
\text { mA }}}$} & & \\
\hline & & & & $\begin{array}{c}\text { Total, } \\
\text { gms }\end{array}$ & $\begin{array}{c}\text { Rate, } \\
\text { mA }\end{array}$ & & & \\
\hline $\begin{array}{l}1969-70 \text { prelaunch testing } \\
1970 \text { normal beam, } 250 \mathrm{~mA} \\
1971-79 \text { restarts/storage } \\
1979-80 \text { low beam, } 85 \mathrm{~mA} \\
1980 \text { plasma-mode operation }\end{array}$ & $\begin{array}{r}0-63 \\
63-2080 \\
2080-2359 \\
2359-2965 \\
2965-3870\end{array}$ & $\begin{array}{r}63 \\
2017 \\
269 \\
606 \\
905\end{array}$ & $\begin{array}{r}1224 \\
5905 \\
\text { b } 76,500 \\
1750 \\
1004\end{array}$ & $\begin{array}{r}20 \\
317 \\
84 \\
133 \\
389\end{array}$ & $\begin{array}{rr} & 21 \pm 3 \\
40 & (e s t) \\
35 \pm 6 \\
\\
45 \pm 6\end{array}$ & $\begin{array}{r}40 \text { (est) } \\
20 \pm 1 \\
36 \pm 2 \\
47 \pm 10\end{array}$ & $\begin{array}{r}23 \\
98 \\
\text { a35 to } 60 \\
98 \\
105\end{array}$ & $\begin{array}{r}0.006 \times 10^{-4} \\
0.4 \times 10^{-4} \\
0.02 \text { to } 0.12 \times 10^{-4} \\
0.4 \times 10^{-4} \\
0.5 \times 10^{-4}\end{array}$ \\
\hline $\begin{array}{l}1980 \text { cold, Hg tank empty } \\
1980 \text { hot, } \mathrm{Hg} \text { tank empty }\end{array}$ & $\begin{array}{l}4120-6300 \\
6300-9200\end{array}$ & - n & 2170 & $\begin{array}{r}1.1 \\
0 \\
0\end{array}$ & $\begin{array}{l}0 \\
0 \\
0\end{array}$ & -ב--- & $\begin{array}{r}60 \\
105\end{array}$ & $\begin{array}{l}1.8 \times 10^{-4} \\
7.2 \times 10^{-4}\end{array}$ \\
\hline
\end{tabular}

aTemperature range due to various lengths of spacecraft shadowing periods.

bHg lost through vaporizer during storage periods was calculated at $0.5 \mathrm{gm}$ total for mission.

$\mathrm{CN}_{2}$ pressure at zero counts $\left(<0.17 \mathrm{~N} / \mathrm{cm}^{2}\right)$.

TABLE 7: - SUMMARY OF ESTIMATED FLOW RATES, MAIN TANK, SYSTEM 1

\begin{tabular}{|c|c|c|c|}
\hline Operating period & $\underset{\mathrm{hr}}{\text { Time, }}$ & $\begin{array}{l}\text { Est imated } \\
\text { flow, } \\
\text { mA }\end{array}$ & $\begin{array}{l}\mathrm{Hg}, \\
\mathrm{gm}\end{array}$ \\
\hline $\begin{array}{l}1969 \text { pre launch testing } \\
1970 \text { full beam ( } 250 \mathrm{~mA}) \\
1970-72 \text { short-clearing tests } \\
1973-78 \text { operation (146 starts) } \\
240 \text { starts: prestart overshoot } \\
1979-80 \text { discharge operation: } \\
\text { C anode }(40 \mathrm{v} .) \\
\text { B anode (33 v.) } \\
\text { Total used, estimated } \\
\text { Total loaded (usefui) } \\
\text { Difference (1.6 percent) }\end{array}$ & $\begin{array}{r}83 \\
3794 \\
72 \\
36 \\
-- \\
\\
553 \\
3390\end{array}$ & $\begin{array}{l}291 \\
291 \\
100 \\
135 \\
--- \\
-- \\
135 \\
184\end{array}$ & $\begin{array}{r}181 \\
8,260 \\
54 \\
a_{41} \\
62 \\
9 \\
563 \\
4,660 \\
13,830 \\
14,050 \\
220\end{array}$ \\
\hline
\end{tabular}

a Includes $4 \mathrm{gm} \mathrm{Hg}$ estimated lost through vaporizer during storage periods $\left(30^{\circ}\right.$ to $\left.50^{\circ} \mathrm{C}\right)$. 




VEHICLE COORDINATE SYSTEM IN ORBIT VIEWED FROM SUN

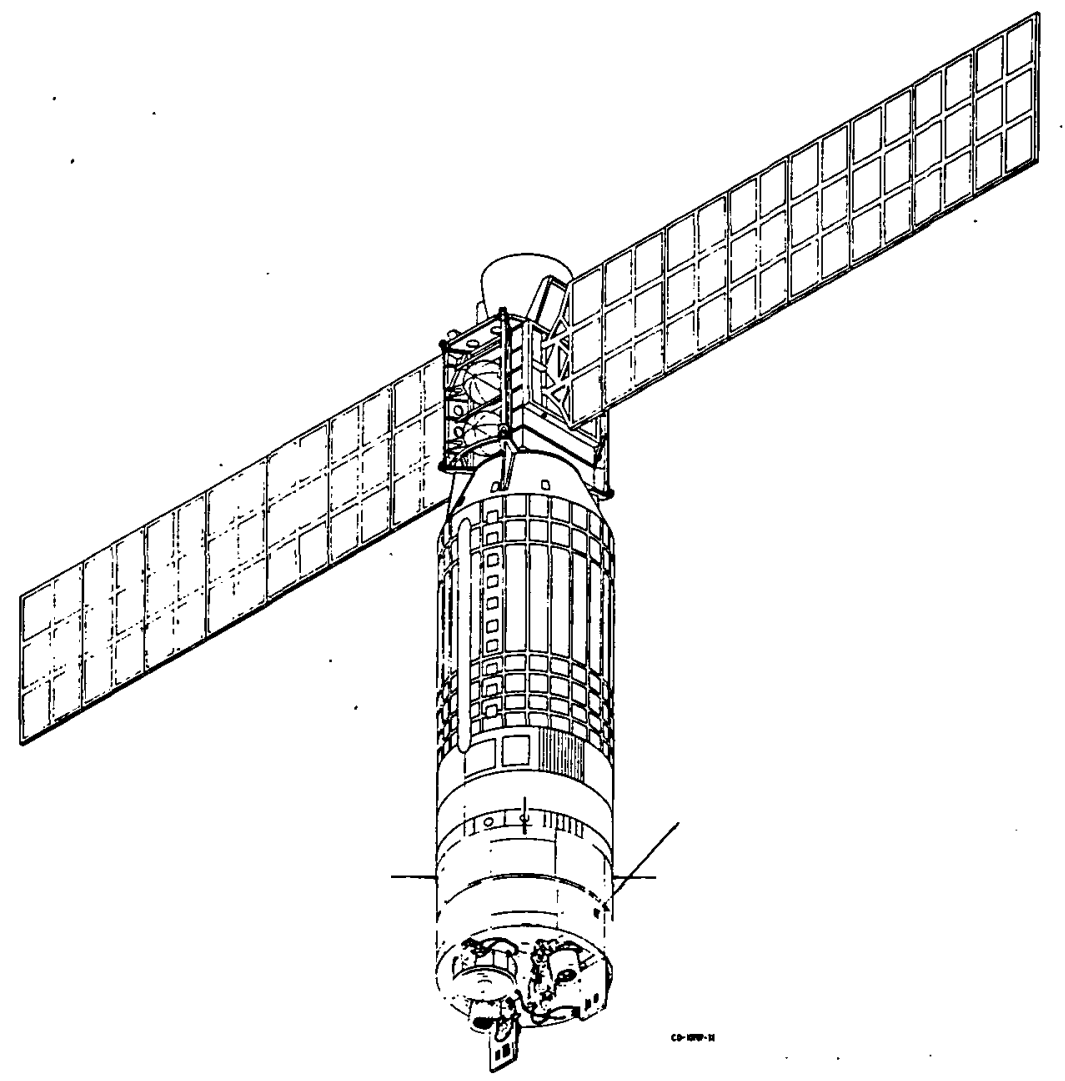

Figure 1. - SERT II spacecraft in orbit (artist's conception). 

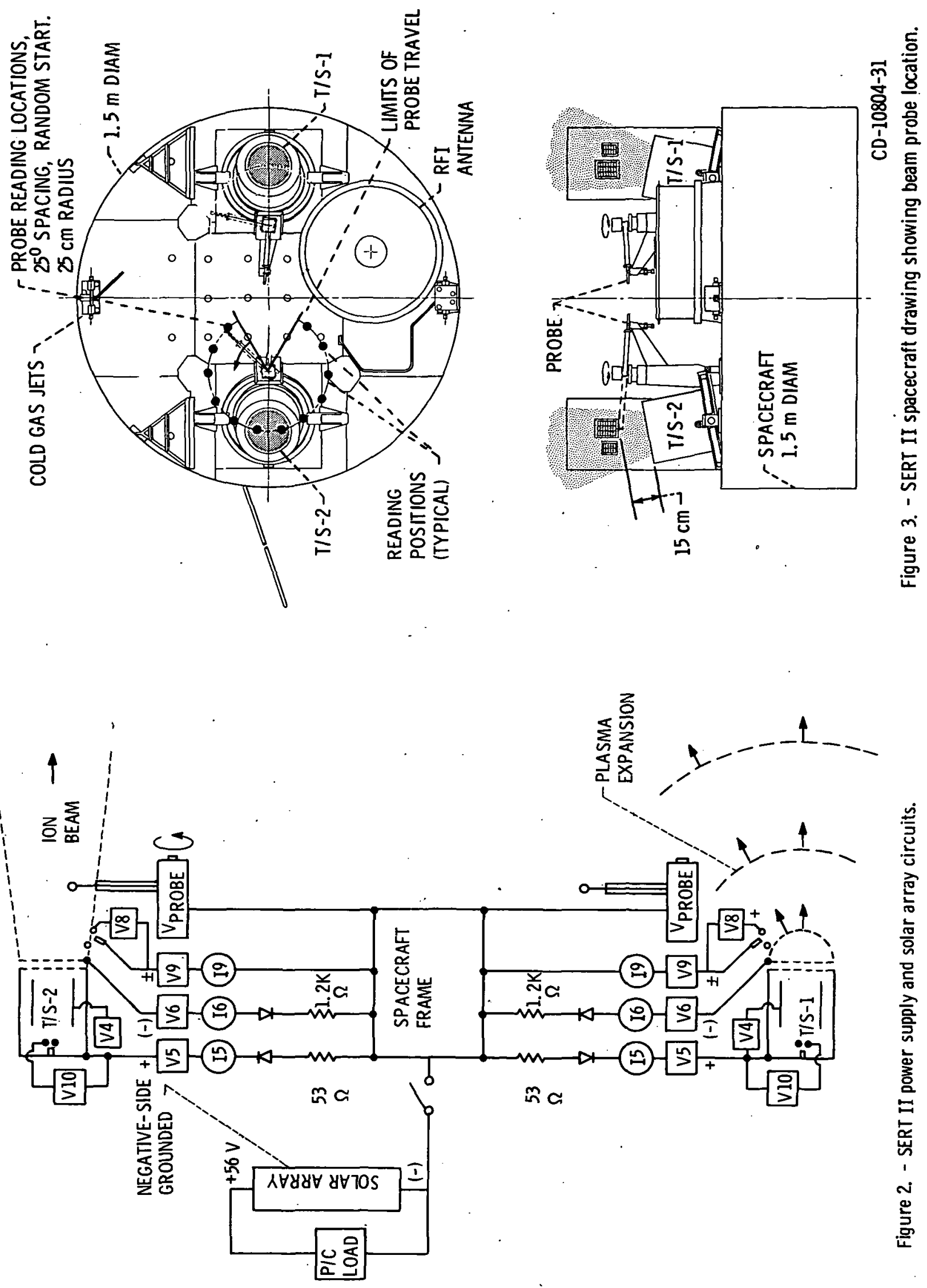


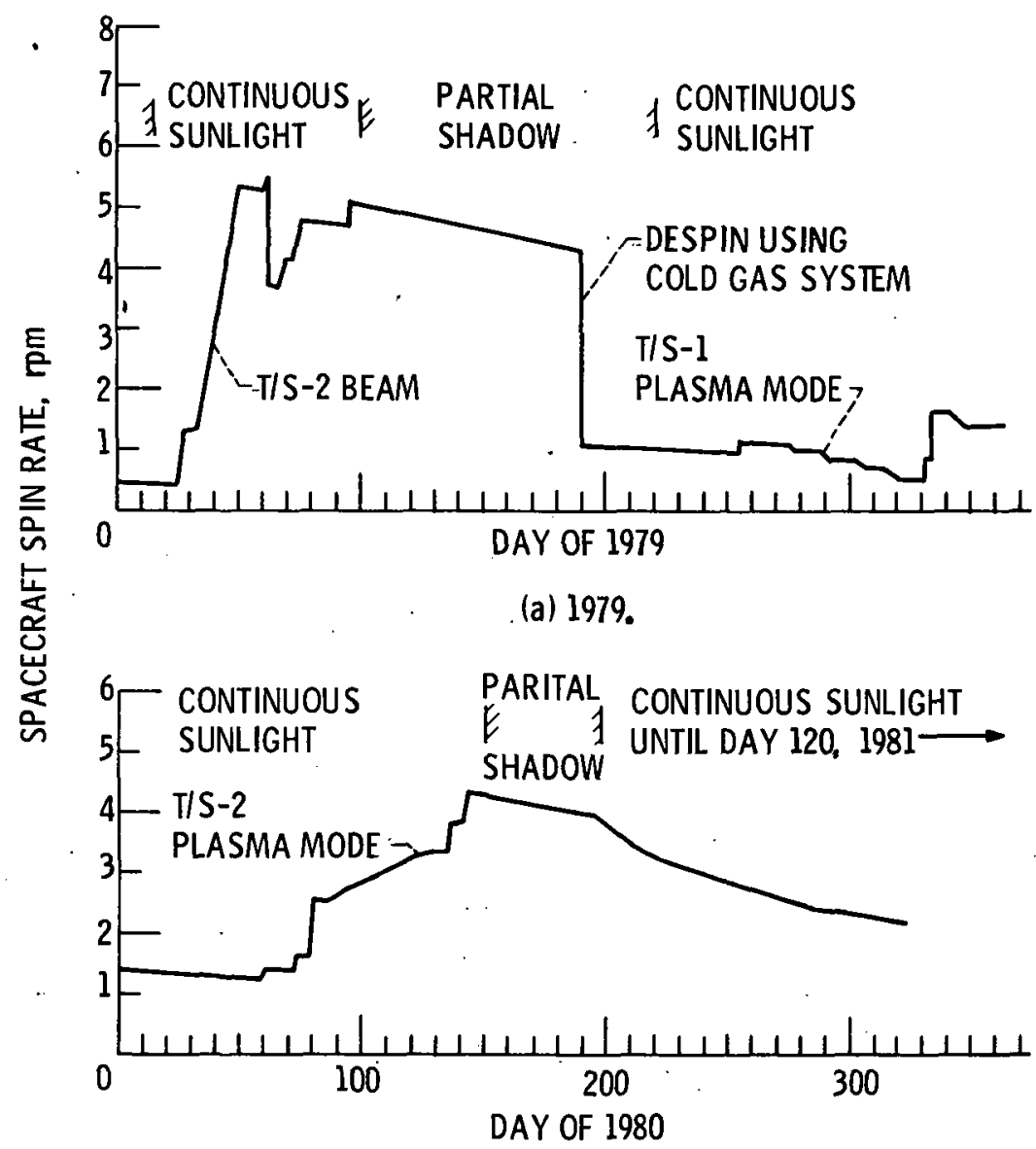

(b) 1980

Figure 4. - Plot of SERT II spacecraft spin rate. 


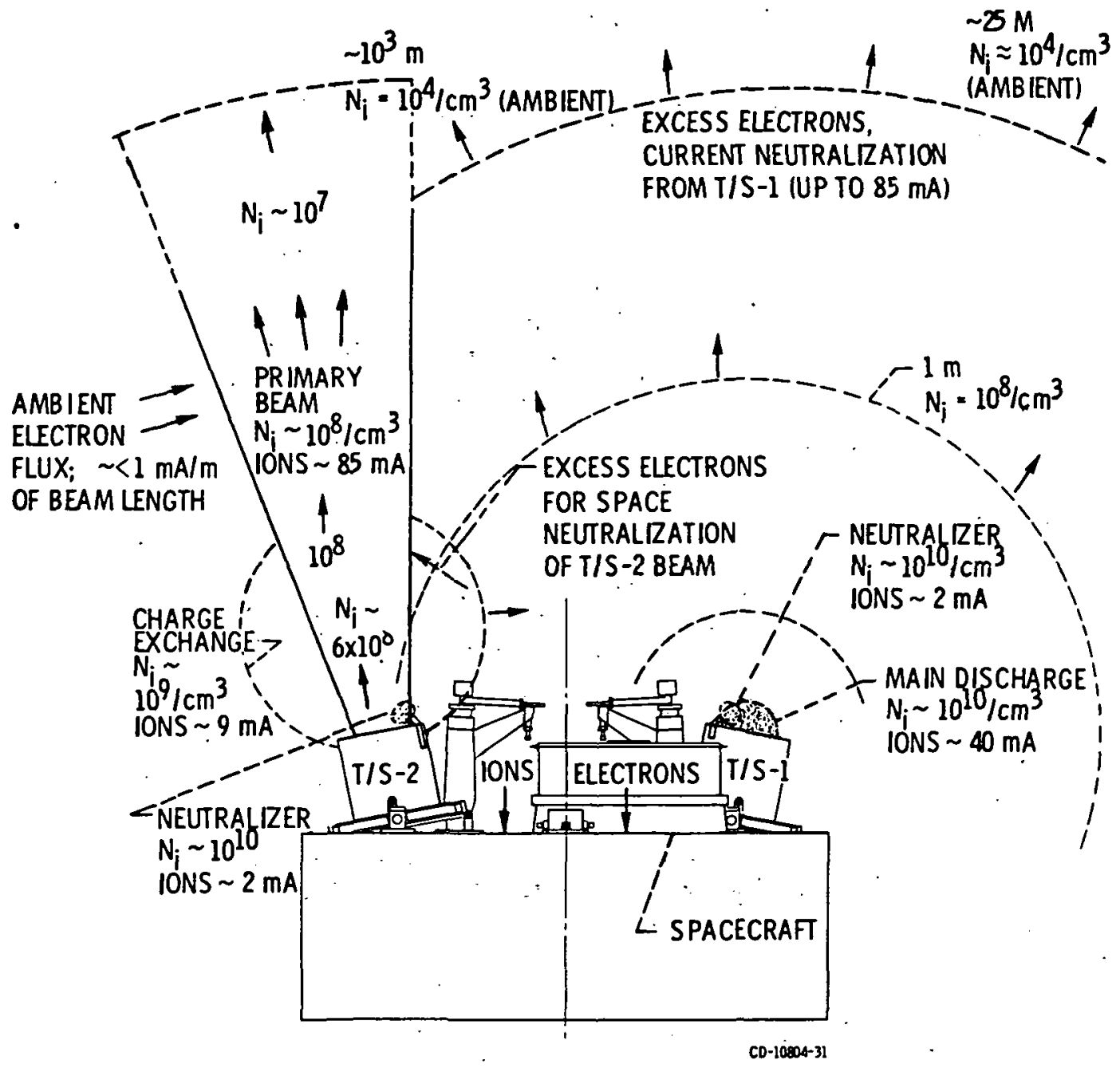

Figure 5. - Spacecraft plasma current diagram. 

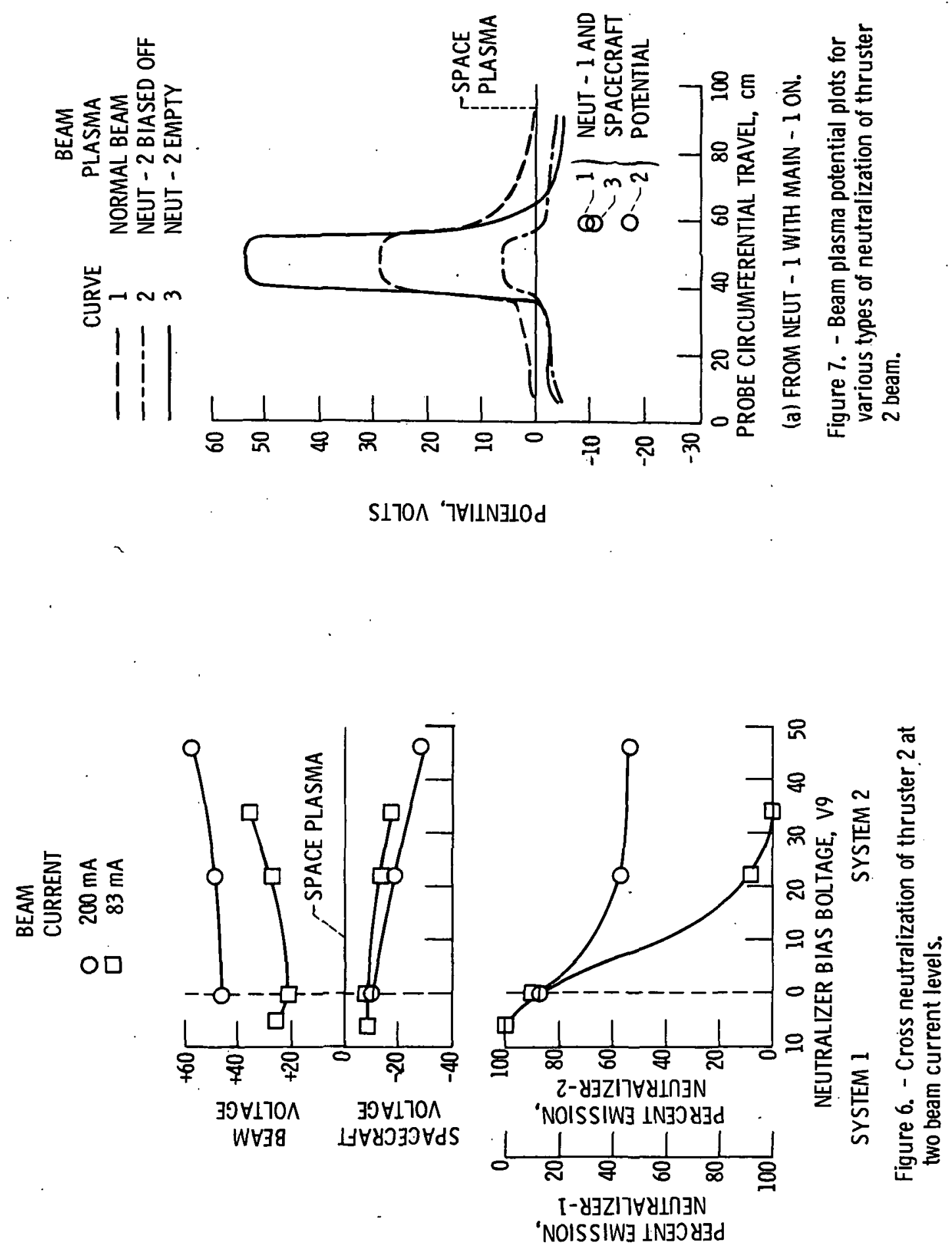

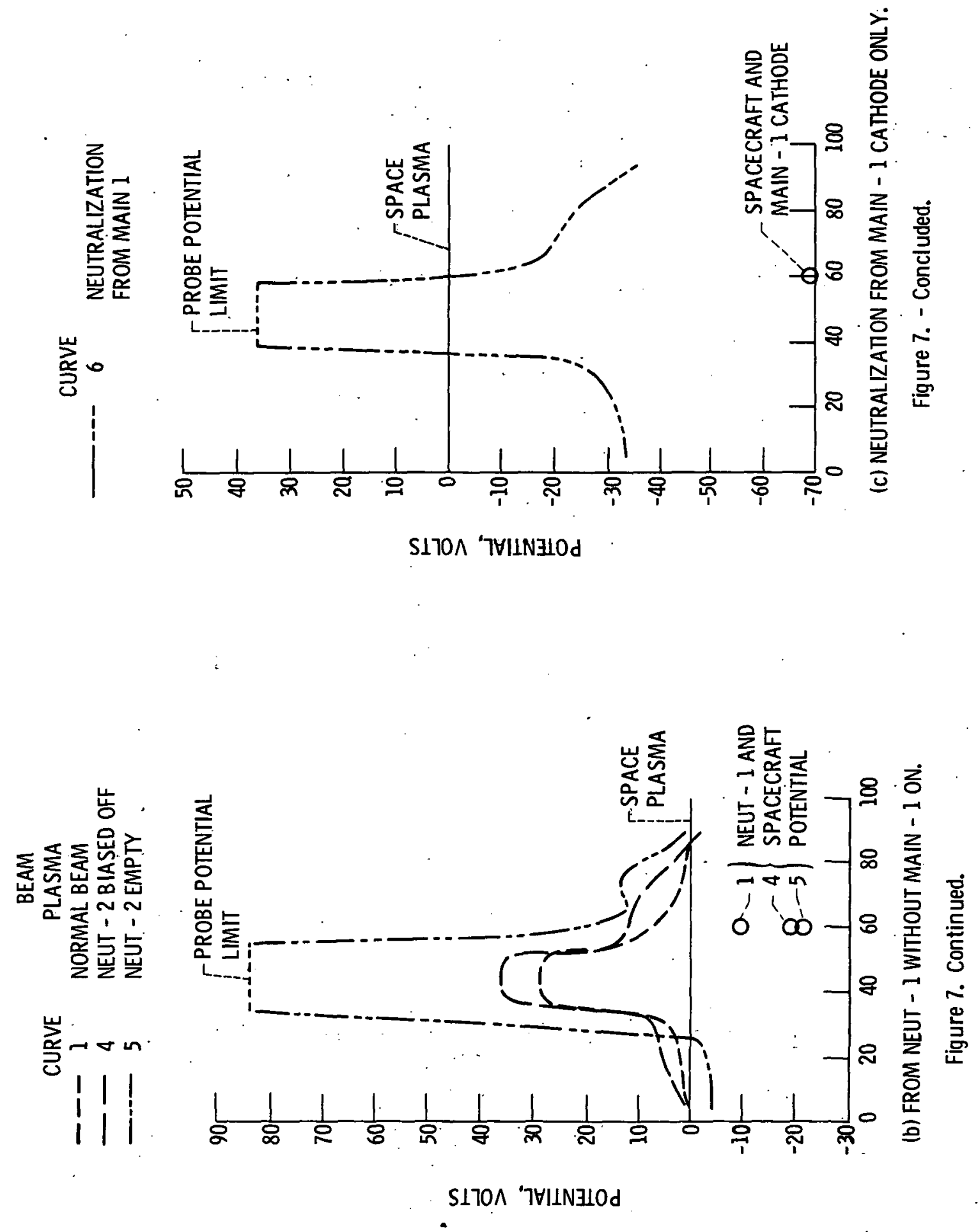


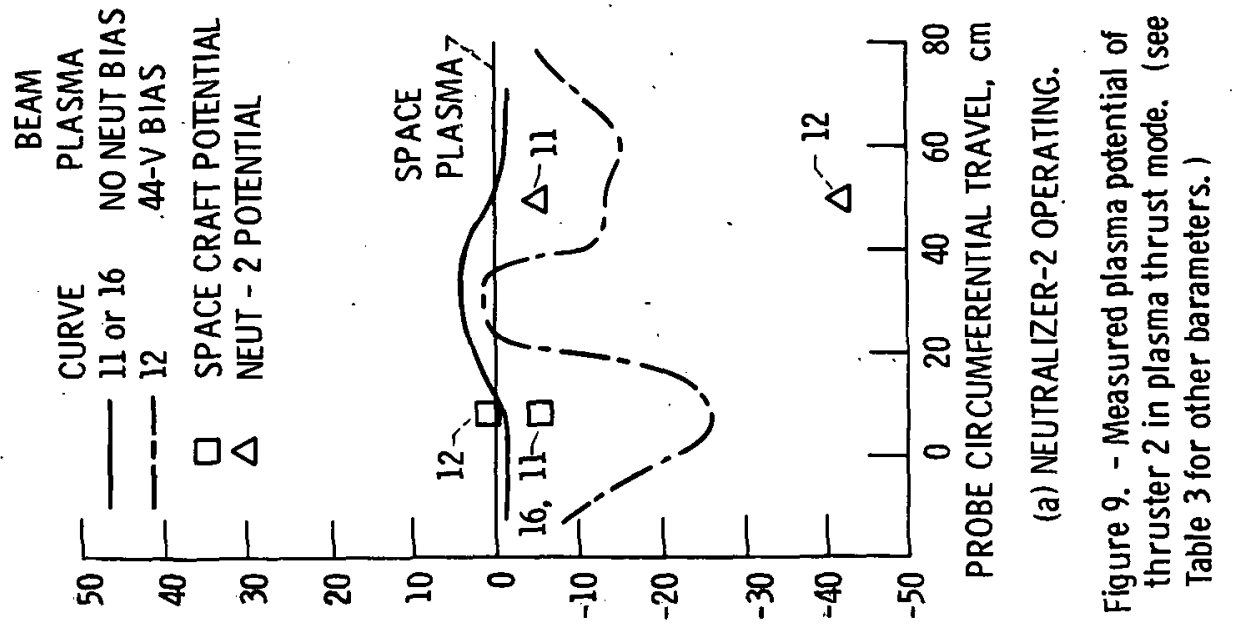

$\wedge$ '7VIINAIOd





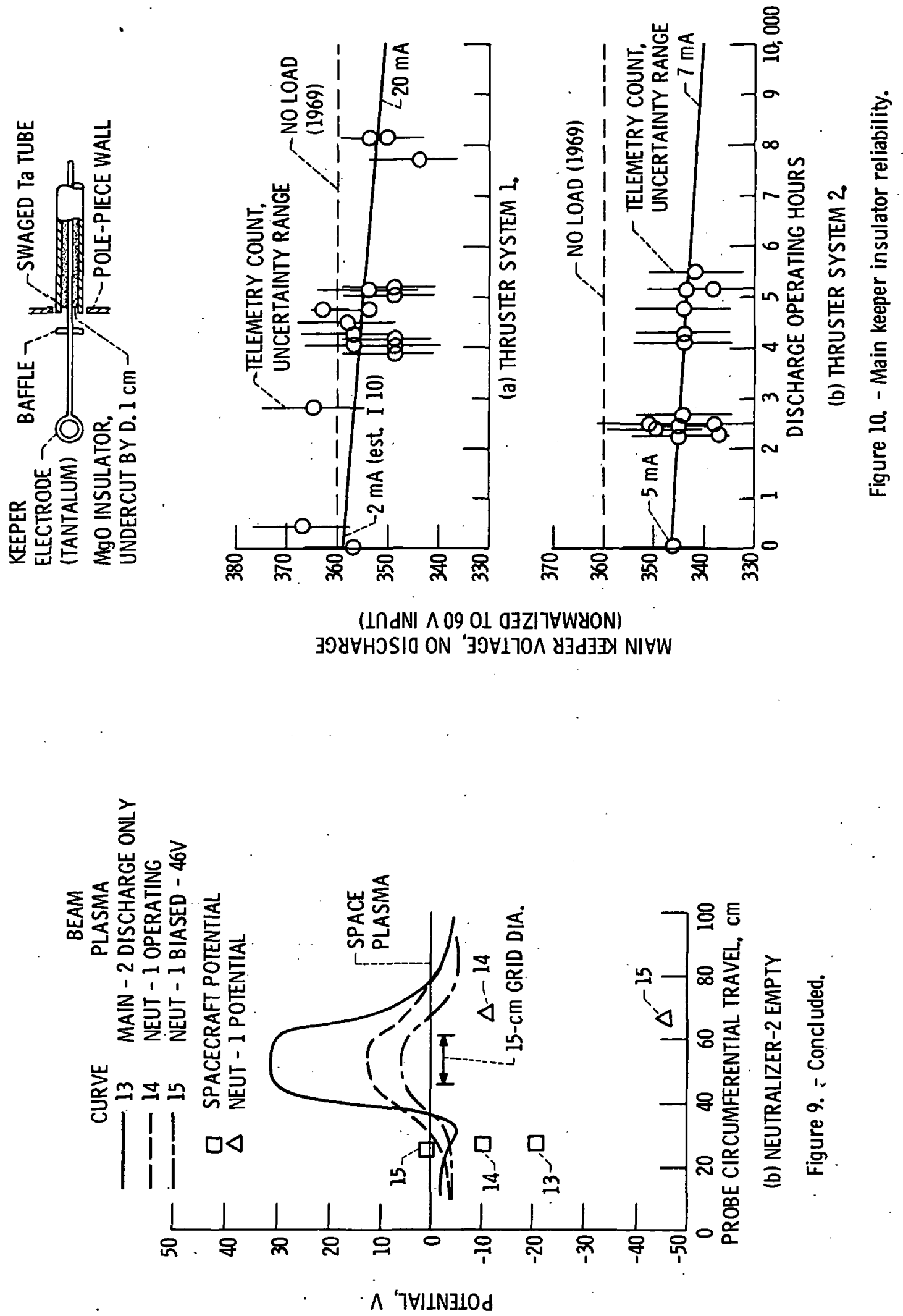

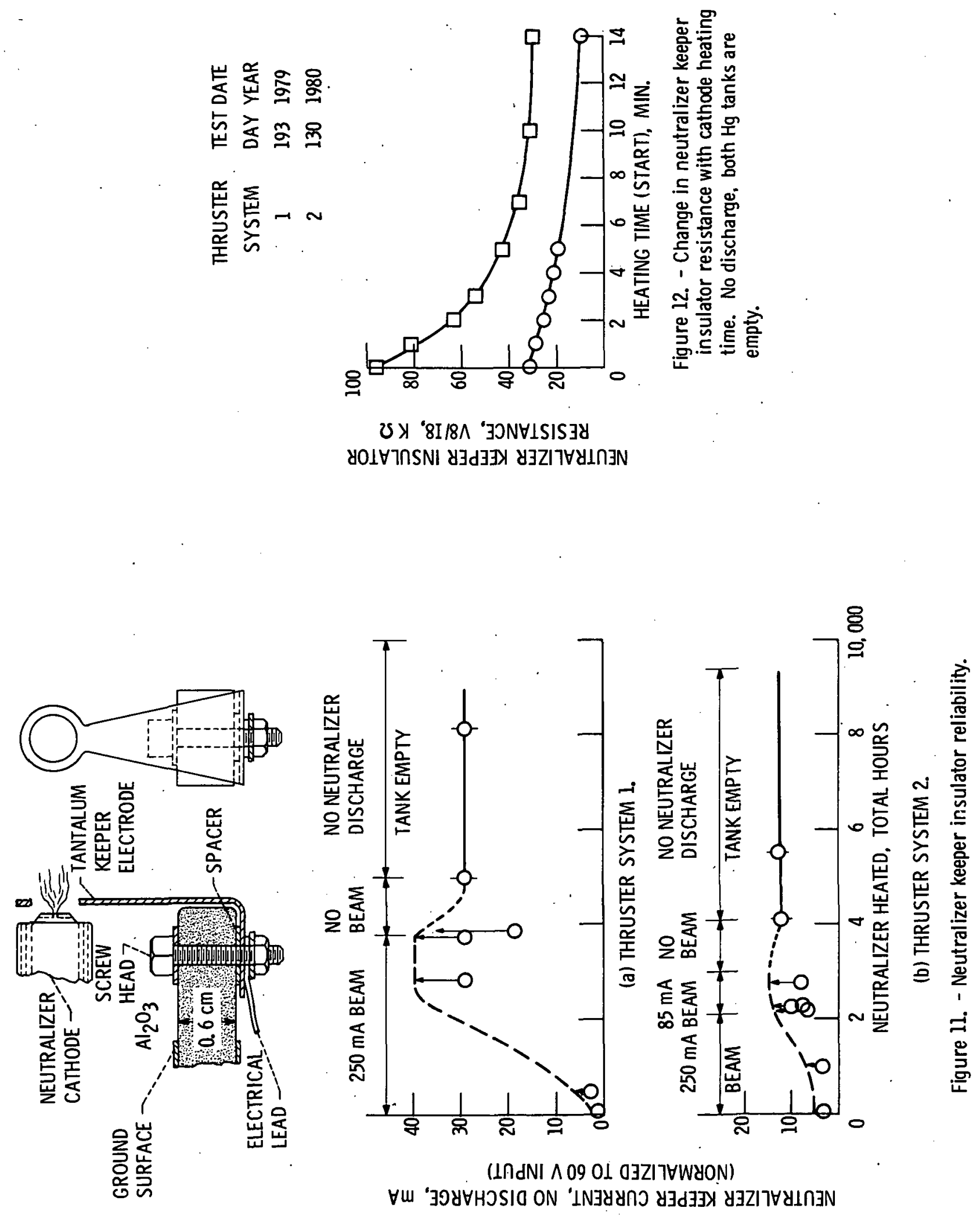


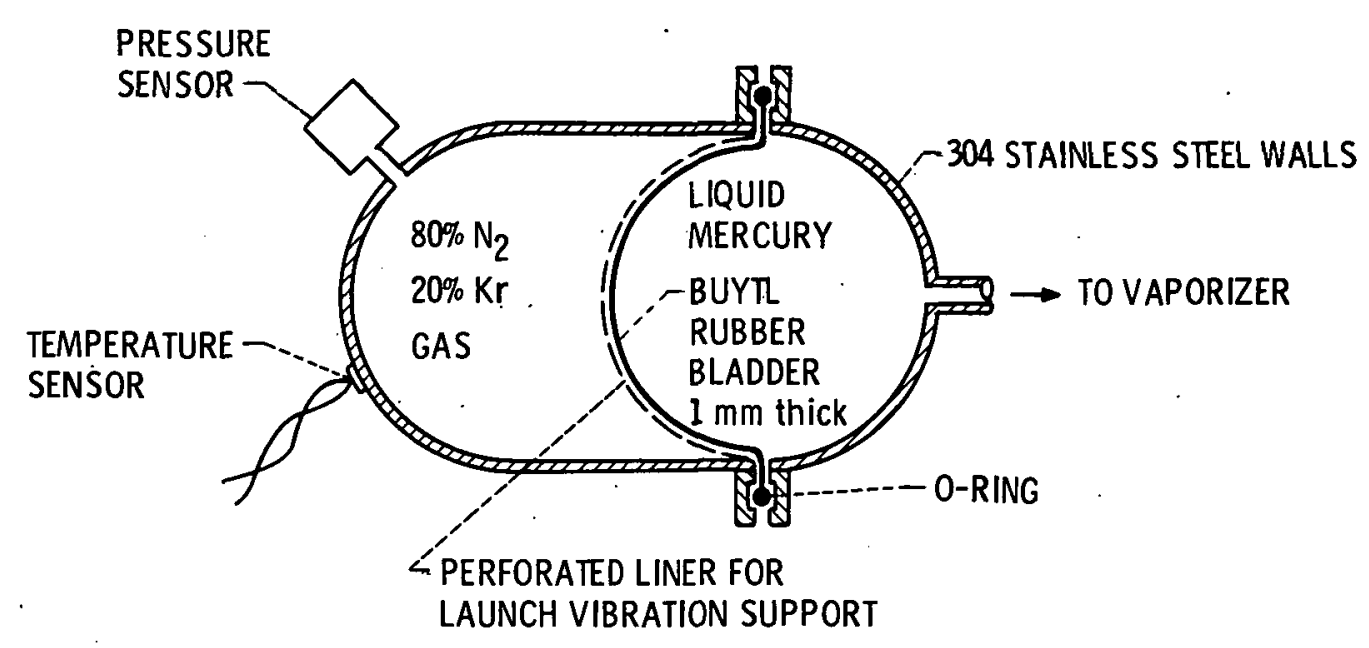

Figure 13. - Schematic of neutralizer propellant tank construction design.

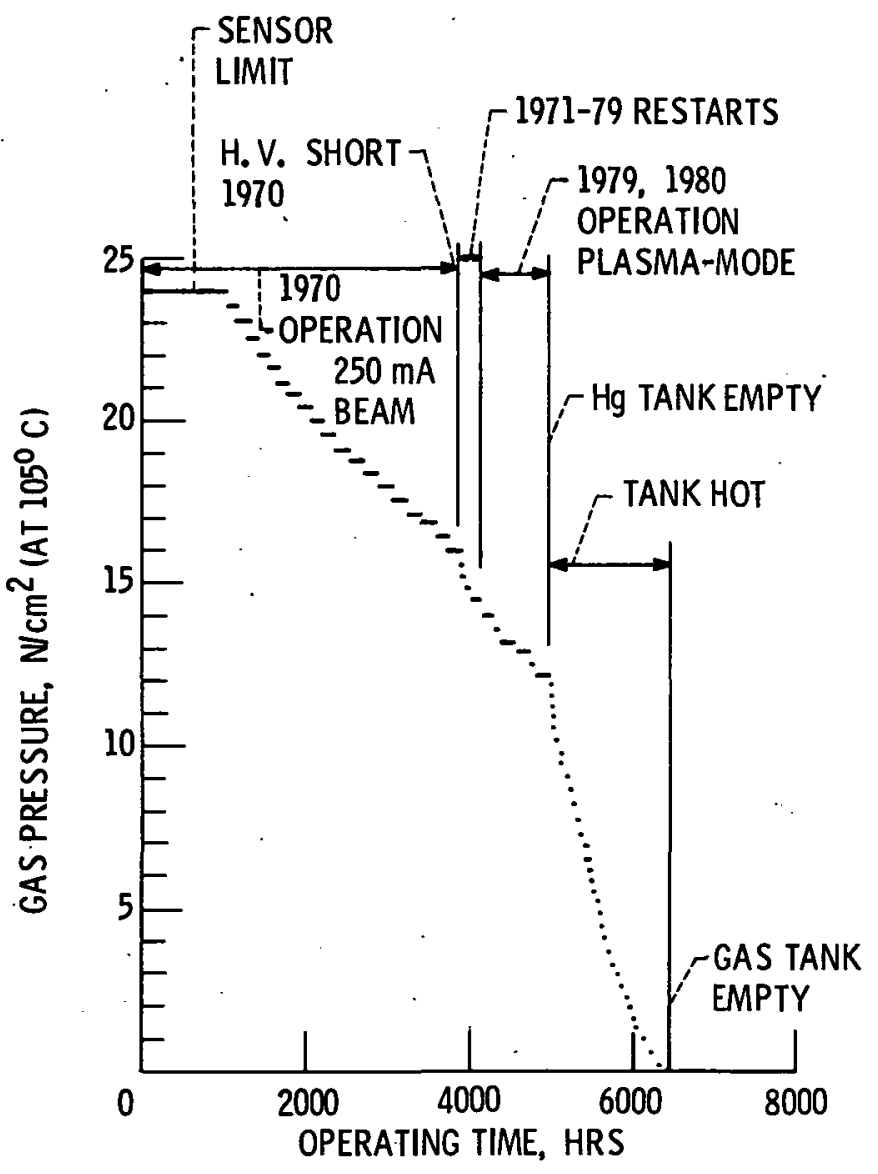

(a) NEUTRALIZER TANK - 1.

Figure 14. - History of neutralizer tank pressure. 




(b) NEUTRALIZER TANK - 2.

Figure 14. - Concluded. History of neutralizer tank pressure. 


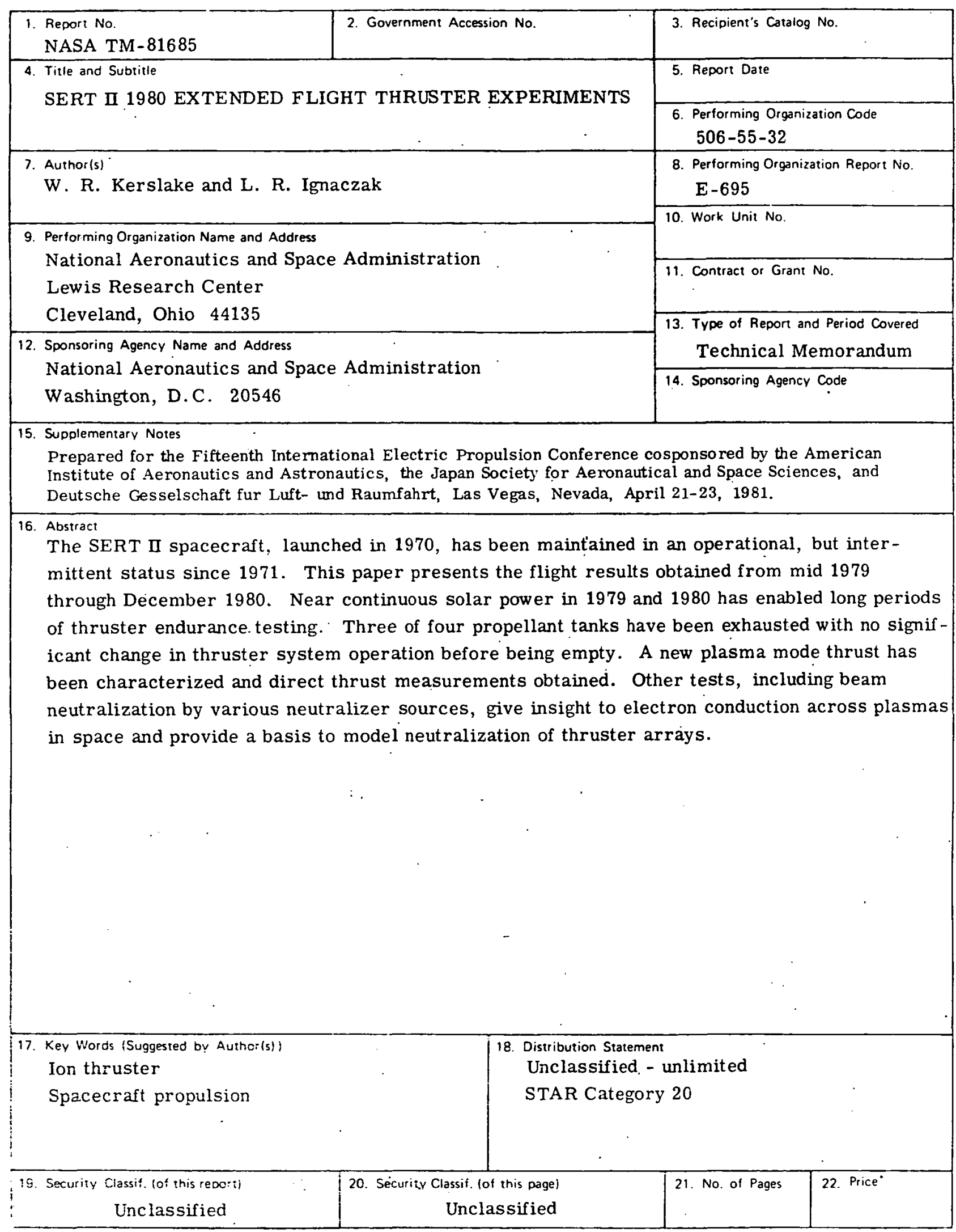

Fo: sale by the Haional Techricai Irifomation Service. Springileld. Virginia 22161 
National Aeronautics and Space Administration BOOK

Washington, D.C.

20546

Official Business

Penalty for Private Use, $\$ 300$
Postage and Fees Paid National Aeronautics and Space Administration NASA-451

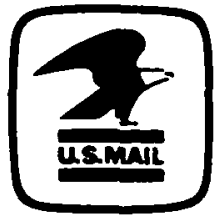

